\title{
Sources of cortical rhythms change as a function of cognitive impairment in pathological aging: a multicenter study
}

\author{
Claudio Babiloni ${ }^{\mathrm{a}, \mathrm{b}, \mathrm{c}, *}$, , Giuliano Binetti ${ }^{\mathrm{b}}$, Emanuele Cassetta ${ }^{\mathrm{c}}$, Gloria Dal Forno ${ }^{\mathrm{d}}$, Claudio \\ Del Percio ${ }^{\mathrm{a}, \mathrm{b}, \mathrm{c}}$, Florinda Ferreri ${ }^{\mathrm{c}, \mathrm{d}}$, Raffaele Ferri ${ }^{\mathrm{e}}$, Giovanni Frisoni ${ }^{\mathrm{b}, \mathrm{c}}$, Koichi Hirata ${ }^{\mathrm{f}}$, \\ Bartolo Lanuzza ${ }^{\mathrm{e}}$, Carlo Miniussi ${ }^{\mathrm{b}}$, Davide V. Moretti ${ }^{\mathrm{c}}$, Flavio Nobili ${ }^{\mathrm{g}}$, Guido Rodriguez ${ }^{\mathrm{g}}$, \\ Gian Luca Romani ${ }^{\text {h,i }}$, Serenella Salinari ${ }^{\mathrm{j}}$, Paolo M. Rossini ${ }^{\mathrm{b}, \mathrm{c}, \mathrm{d}}$ \\ ${ }^{a}$ Dip. Fisiologia Umana e Farmacologia, Univ. 'La Sapienza' Rome, Italy \\ b IRCCS 'S. Giovanni di Dio-F.B.F.', Brescia, Italy \\ ${ }^{c}$ A.Fa.R., Dip. Neurosci. Osp. FBF; Isola Tiberina, Rome, Italy \\ 'Clin. Neurol. University 'Campus Biomedico' Rome, Italy \\ ${ }^{\mathrm{e}}$ Department of Neurology, Oasi Institute for Research on Mental Retardation and Brain Aging (IRCCS), Troina, Italy \\ ${ }_{\mathrm{f}}^{\mathrm{f}}$ Department of Neurology Dokkyo University School of Medicine (Japan) \\ ${ }^{\mathrm{g}}$ Division of Clinical Neurophysiology (DISEM), University of Genova, Italy \\ ${ }^{\mathrm{h}}$ Dipartimento di Scienze Cliniche e Bioimmagini, Università G. D'Annunzio, Chieti, Italy \\ ' ITAB - Fondazione 'Università G. D'Annunzio', Chieti, Italy \\ ${ }^{\mathrm{j}}$ Dipartimento Informatica e Sistemistica Univ. 'La Sapienza', Rome, Italy
}

Accepted 23 September 2005

Available online 27 December 2005

\begin{abstract}
Objective: The present study tested the hypothesis that cortical electroencephalographic (EEG) rhythms. change across normal elderly (Nold), mild cognitive impairment (MCI), and Alzheimer's disease (AD) subjects as a function of the global cognitive level.

Methods: Resting eyes-closed EEG data were recorded in $155 \mathrm{MCI}, 193$ mild AD, and 126 age-matched Nold subjects. EEG rhythms of interest were delta $(2-4 \mathrm{~Hz})$, theta $(4-8 \mathrm{~Hz})$, alpha $1(8-10.5 \mathrm{~Hz})$, alpha $2(10.5-13 \mathrm{~Hz})$, beta $1(13-20 \mathrm{~Hz})$, and beta $2(20-30 \mathrm{~Hz})$. EEG cortical sources were estimated by LORETA.

Results: Occipital delta and alpha 1 sources in parietal, occipital, temporal, and 'limbic' areas had an intermediate magnitude in MCI subjects compared to mild AD and Nold subjects. These five EEG sources presented both linear and nonlinear (linear, exponential, logarithmic, and power) correlations with the global cognitive level (as revealed by mini mental state examination score) across all subjects.

Conclusions: Cortical EEG rhythms change in pathological aging as a function of the global cognitive level.

Significance: The present functional data on large populations support the 'transitional hypothesis' of a shadow zone across normality, pre-clinical stage of dementia (MCI), and AD.

(C) 2005 International Federation of Clinical Neurophysiology. Published by Elsevier Ireland Ltd. All rights reserved.
\end{abstract}

Keywords: Mild cognitive impairment (MCI); Mild Alzheimer's disease (mild AD); Electroencephalography (EEG); Alpha rhythm; Low resolution brain electromagnetic tomography (LORETA)

\footnotetext{
* Corresponding author. Address: Dipartimento di Fisiologia Umana e Farmacologia, Università degli Studi di Roma 'La Sapienza', P.le Aldo Moro 5, 00185 Rome, Italy. Tel.: +39 0649910989 ; fax: + 39649910917.

E-mail address: claudio.babiloni@uniroma1.it (C. Babiloni).

URL: http://hreeg.ifu.uniroma1.it/.
}

\section{Introduction}

Recent advances for early diagnosis of Alzheimer disease $(\mathrm{AD})$ have led researchers to focus on presymptomatic phases of the disease (Arnaiz and Almkvist, 2003; Galluzzi et al., 2001; Scheltens et al., 2002). In this vein, mild cognitive impairment (MCI) has often been considered 
as a precursor of AD. It is a clinical condition characterized by memory impairment not causing functional impairment and not meeting criteria for a diagnosis of dementia (Flicker et al., 1991; Petersen et al., 1995; 2001).

Recent studies have shown a very high risk of progression to AD in MCI subjects (Bachman et al., 1993; Gao et al., 1998; Petersen et al., 2001). In normal aging (with no MCI symptoms), annual conversion rate to $\mathrm{AD}$ ranges from $0.17 \%$ at age $65-69$ to $3.86 \%$ at age $85-89$, whereas the cumulative rate for all dementias ranges from 0.82 to $5.33 \%$ (Petersen et al., 2001). At the same ages, instead, the annual conversion rate from MCI to AD seems to be much higher, ranging from 6 to $25 \%$ (Petersen et al., 2001). Furthermore, an influential longitudinal study has shown that MCI converts to $\mathrm{AD}$ at a rate of $12 \%$ per year (Petersen et al., 1999) and, at the end of 6 years, approximately $80 \%$ of MCI subjects had developed AD. Taken together, these data suggest the hypothesis that MCI is a transition state on a linear progression towards mild AD. According to such a hypothesis, early identification of MCI patients might be crucial to start rehabilitative or pharmacological interventions aimed at slowing the progression of cognitive deficits and onset of disability (Braak et al., 1991; Rogers et al., 1996; Small et al., 1997).

A great deal of attention has been directed to electrophysiological substrate of $\mathrm{AD}$ and $\mathrm{MCI}$, to evaluate the 'transition' hypothesis of a linear progression from MCI to mild $\mathrm{AD}$. In mild $\mathrm{AD}$, electroencephalographic (EEG) rhythms differ from normal elderly (Nold) and vascular dementia subjects, AD patients being characterized by higher delta $(0-3 \mathrm{~Hz})$ and lower posterior alpha $(8-12 \mathrm{~Hz}$; Babiloni et al., 2004a; Dierks et al., 1993; 2000; Huang et al., 2000; Moretti et al., 2004). Abnormality of EEG rhythms in dementia has been associated with altered regional cerebral blood flow $(\mathrm{rCBF}) /$ metabolism and cognitive function (Celsis et al., 1990; Ihl et al., 1989; Joannesson et al., 1977; Julin et al., 1995; Nobili et al., 2002a,b; 1999a,b; Sheridan et al., 1988; Sloan et al., 1995; Szelies et al., 1992). Furthermore, parieto-temporal EEG rhythms and rCBF have been correlated with severity of AD as expressed by Mini Mental State Examination (MMSE) score (Rodriguez et al., 1998). Similarly, MCI subjects have shown increase of theta $(4-7 \mathrm{~Hz})$ power (Grunwald et al., 2001; Jelic et al., 1996; Zappoli et al., 1995) as well as decrease of alpha power (Frodl et al., 2002; Grunwald et al., 2002; Grunwald et al., 2001; Huang et al., 2000; Jelic et al., 1996; Zappoli et al., 1995), when compared to normal elderly (Nold) subjects. In line with the 'transition' hypothesis, these EEG parameters have presented an intermediate magnitude in MCI subjects with respect to those observed in Nold and dementia patients (Elmstahl and Rosen, 1997; Huang et al., 2000; Jelic et al., 2000).

'Transition' hypothesis, however, is challenged by observations indicating that not all MCI patients deteriorate over time (Bennett et al., 2002; Larrieu et al., 2002). In fact, the risk of $\mathrm{AD}$ in MCI subjects has been shown to be higher than in normal controls only during the first 4 years of follow up (Bennett et al., 2002). Furthermore, previous evidence has indicated that cumulative conversion rates from MCI to AD have ranged from 40 to $60 \%$, depending on the studies (Bennett et al., 2002; Fisk et al., 2003; Larrieu et al., 2002). Practical consequence of these observations is that a diagnosis of MCI might be clinically not relevant because of the uncertainty of the conversion to dementia.

The present study used cortical sources of resting EEG rhythms as a functional probe to test the 'transitional' hypothesis of a shadow zone across normality, pre-clinical stage of dementia (MCI), and mild AD. The prediction of the 'transitional' hypothesis was that the resting cortical EEG rhythms would correlate with the global cognitive status of Nold, MCI, and AD subjects considered as a unique group. Cortical sources of the EEG rhythms were estimated by low-resolution brain electromagnetic tomography (LORETA; Pascual-Marqui and Michel, 1994, 1999, 2002), which has been successfully used in recent studies on physiological and pathological aging (Babiloni et al., 2004a, 2005a; Dierks et al., 2000).

\section{Methods}

We have been extensively described in two recent papers part of the procedures (EEG recordings and LORETA analysis) pertinent to the current study as well as a description of the potential meaning of cortical rhythms in aging (Babiloni et al., 2004a, 2005a). However, it should be stressed that the aims of the previous studies the and current one are totally different. The previous studies aimed at analyzing (i) the distributed EEG sources specific to mild $\mathrm{AD}$ as compared to vascular dementia or normal aging (Babiloni et al., 2004a); and (ii) the distributed EEG sources during physiological aging (Babiloni et al., 2005a). In contrast, the current study focused on the distributed EEG sources in a very large group of MCI subjects when compared to control groups including mild $\mathrm{AD}$ and Nold subjects.

\subsection{Subjects}

For the present multicenter study, we enrolled $155 \mathrm{MCI}$ subjects, 193 AD patients and 126 Nold subjects as controls. Local institutional ethics committees approved the study. All experiments were performed with the informed and overt consent of each participant or caregiver, in line with the Code of Ethics of the World Medical Association (Declaration of Helsinki) and the standards established by the Author's Institutional Review Board. The recruitment of subjects began in the year 2000 by five Italian clinical centres (University 'Campus Biomedico' of Rome; Fatebenefratelli Hospital of Brescia; Fatebenefratelli Hospital of Rome; OASI Institute of Troina; University of Genova) and one Japanese clinical centre (Dokkyo University School, 
Japan). The mean contribution of these clinical units to the data collection was $16.7( \pm 3.9 \%$ standard error, SE).

\subsection{Diagnostic criteria}

Probable AD was diagnosed according to NINCDSADRDA (McKhann et al., 1984) and DSM IV criteria. The recruited $\mathrm{AD}$ patients underwent general medical, neurological and psychiatric assessments. Patients were also rated with a number of standardized diagnostic and severity instruments that included MMSE (Folstein et al., 1975), clinical dementia rating scale (CDR; Hughes et al., 1982), geriatric depression scale (GDS, Yesavage et al., 1983), hachinski ischemic scale (HIS, Rosen et al., 1980), and instrumental activities of daily living scale (IADL, Lawton and Brodie, 1969). Neuroimaging diagnostic procedures (CT or MRI) and complete laboratory analyses were carried out to exclude other causes of progressive or reversible dementias, in order to have a homogenous mild AD patient sample. Exclusion criteria included, in particular, any evidence of (i) frontotemporal dementia, (ii) vascular dementia (i.e. the vascular dementia was also diagnosed according to NINDS-AIREN criteria; Roman et al., 1993), (iii) extra-pyramidal syndromes, (iv) reversible dementias (including pseudodementia of depression), and (v) fluctuations in cognitive performance (suggestive of a possible Lewy body dementia). The detection of vascular component in dementia and MCI was accounted based on previous theoretical guidelines from our network (Frisoni et al., 1995; Galluzzi et al., 2005). The participating AD patients had MMSE scores ranging from 17 to 24, with a mean of about 21. Of note, benzodiazepines, antidepressant and/or antihypertensive were suspended for about $24 \mathrm{~h}$ before EEG recordings. This did not insure a complete washout of the drug, but made it comparable the drug condition across the patients. Washed out of the drugs would have required a too long suspension of the drugs with high risks for the patients. Of note, about $10 \%$ of $\mathrm{AD}$ patients underwent to therapy with acetylcholinesterase inhibitors at the time of EEG recording (donepezil; 5-10 mg per day; rivastigmine $3 \mathrm{mg}$ per day). Furthermore, about $5 \%$ of the $\mathrm{AD}$ patients were treated with neuroleptics (quetiapine $25 \mathrm{mg}$ per day; risperidone $5 \mathrm{mg}$ per day; olanzapine $2.5 \mathrm{mg}$ per day).

The present inclusion and exclusion criteria for MCI diagnosis were based on previous seminal studies (Albert et al., 1991; Devanand et al., 1997; Flicker et al., 1991; Petersen et al., 1995, 1997; 2001; Rubin et al., 1989; Zaudig; 1992) and aimed at selecting elderly persons with objective cognitive deficits, especially in the memory domain, who did not meet criteria for a diagnosis of dementia or AD. Inclusion criteria for MCI subjects were the following: (i) objective memory impairment on neuropsychological evaluation, as defined by performances $\geq 1.5$ standard deviation below age and education-matched controls; (ii) normal activities of daily living as documented by the history and evidence of
Table 1

Demographic and neuropsychological data of interest of normal aging (Nold), mild cognitive impairment (MCI) and mild Alzheimer's disease (AD) subjects

\begin{tabular}{llll}
\hline & Nold & MCI & Mild AD \\
\hline $\mathrm{N}$ & 126 & 155 & 193 \\
Age (years) & $65.4( \pm 0.9 \mathrm{SE})$ & $72.1( \pm 0.7 \mathrm{SE})$ & $76.2( \pm 0.6 \mathrm{SE})$ \\
$\begin{array}{l}\text { Gender (F/M) } \\
\text { MMSE }\end{array}$ & $76 / 50$ & $97 / 58$ & $151 / 42$ \\
$\begin{array}{l}\text { Education } \\
\text { (years) }\end{array}$ & $9.7( \pm 0.1 \mathrm{SE})$ & $25.9( \pm 0.2 \mathrm{SE})$ & $20.7( \pm 0.2 \mathrm{SE})$ \\
$\begin{array}{l}\text { Disease dur- } \\
\text { ation (months) }\end{array}$ & - & $7.4( \pm 0.3 \mathrm{SE})$ & $6.7( \pm 0.3 \mathrm{SE})$ \\
\hline
\end{tabular}

independent living; (iii) clinical dementia rating score of 0.5 ; and (iv) MMSE score of 24-27. Exclusion criteria for MCI were: (i) mild $\mathrm{AD}$, as diagnosed by the procedures described above; (ii) evidence of concomitant dementia such as frontotemporal, vascular dementia, reversible dementias (including pseudo-depressive dementia), fluctuations in cognitive performance, and/or features of mixed dementias; (iii) evidence of concomitant extra-pyramidal symptoms; (iv) clinical and indirect evidence of depression as revealed by GDS scores lower than 14; (v) other psychiatric diseases, epilepsy, drug addiction, alcohol dependence, and use of psychoactive drugs including acetylcholinesterase inhibitors or other drugs enhancing brain cognitive functions; and (vi) current or previous systemic diseases (including diabetes mellitus) or traumatic brain injuries.

Nold subjects were recruited mainly among patients' spouses. All Nold subjects underwent physical and neurological examinations as well as cognitive screening (including MMSE). Subjects affected by chronic systemic illnesses (i.e. diabetes mellitus or organ failure) were excluded, as were subjects receiving psychoactive drugs. Subjects with a history of present or previous neurological or psychiatric disease were also excluded. All Nold subjects had a GDS score lower than 14.

Table 1 reports the mean values of relevant personal and clinical parameters of participating mild $\mathrm{AD}, \mathrm{MCI}$, and Nold subjects. As expected, women were overrepresented in the AD group. Three ANOVA analyses using the factor Group (Nold, MCI, AD) were computed to evaluate the presence or absence of statistically significant differences among the Nold, MCI, and mild AD groups for age, education, and gender. Statistically significant differences for age $(P<0.001)$, education $(P<0.001)$, and gender $(P<0.009)$ were found. Among these variables, age and education were used as covariates in the statistical evaluation of cortical sources of EEG rhythms, to remove possible confounding effects.

\subsection{EEG recordings}

EEG data were recorded in resting subjects (eyes-closed) by specialized clinical units. EEG recordings were 
performed (0.3-70 Hz bandpass) from 19 electrodes positioned according to the International 10-20 System (i.e. Fp1, Fp2, F7, F3, Fz, F4, F8, T3, C3, Cz, C4, T4, T5, $\mathrm{P} 3, \mathrm{Pz}, \mathrm{P} 4, \mathrm{~T} 6, \mathrm{O} 1, \mathrm{O} 2)$. A specific kind of reference electrode was not imposed to all recording units of this multicenter study, given that preliminary data analysis and LORETA source analysis were carried out after that EEG data were re-referenced to common average reference (i.e. all electrodes were included in the average reference). To monitor eye movements, electrooculogram $(0.3-70 \mathrm{~Hz}$ bandpass) was also collected. All data were digitized in continuous recording mode ( 5 min of EEG; $128-256 \mathrm{~Hz}$ sampling rate, the sampling rate being fixed in each recording research unit of this multicenter study). In all subjects, EEG recordings were performed at late morning. During all EEG recordings, to keep state of vigilance at constant level, an operator controlled on-line the EEG traces and verbally alerted the subject any time there were sign of behavioral drowsiness.

Of note, EEG recordings lasting $5 \mathrm{~min}$ allowed the comparison of the present results with several previous $\mathrm{AD}$ studies using either recording EEG periods no longer than 5 min (Babiloni et al., 2004a,b; Buchan et al., 1997; Muller et al., 1997; Pucci et al., 1999; Rodriguez et al., 2002; Szelies et al., 1999) or EEG periods shorter than $1 \mathrm{~min}$ (Dierks et al., 1993; 2000). Longer resting EEG recordings in $\mathrm{AD}$ patients would have reduced the variability of the data but would have increased the possibility of slowing of EEG oscillations due to reduced vigilance and arousal.

EEG data were analyzed and fragmented off-line in consecutive epochs of $2 \mathrm{~s}$. On average, 150 epochs (5 min) for each subject were examined. For standardization purposes, the preliminary analysis of all data was performed at one of the research units. EEG epochs with ocular, muscular and other types of artifact were preliminary identified by a computerized automatic procedure. The EEG epochs including ocular artifacts (less than $15 \%$ of the total ones) were then corrected by an autoregressive method (Moretti et al., 2003). Two independent experimenters manually confirmed the EEG segments accepted for further analysis. At the end of the preliminary analysis of EEG data, the mean of the individual artifact-free EEG epochs was 120 $( \pm 10 \mathrm{SE})$. This is a sufficient number of 2s-EEG epochs for further LORETA analysis.

\subsection{Spectral analysis of the EEG data}

A digital FFT-based power spectrum analysis (Welch technique, Hanning windowing function, no phase shift) computed power density of EEG rhythms with $0.5 \mathrm{~Hz}$ frequency resolution. The following standard band frequencies were studied: delta $(2-4 \mathrm{~Hz})$, theta $(4-8 \mathrm{~Hz})$, alpha $1(8-10.5 \mathrm{~Hz})$, alpha $2(10.5-13 \mathrm{~Hz})$, beta $1(13-20 \mathrm{~Hz})$, and beta $2(20-30 \mathrm{~Hz})$. These band frequencies were chosen averaging those used in previous relevant EEG studies on dementia (Besthorn et al., 1997; Chiaramonti et al., 1997;
Jelic et al., 1996; Leuchter et al., 1993; Rodriguez et al., 1999a,b) and have been successfully used in recent studies on AD of this Consortium (Babiloni et al., 2004a,b). Sharing of a frequency bin by two contiguous bands was allowed to be consistent with a bulk of EEG literature on dementia (Holschneider et al, 1999; Besthorn et al., 1997; Cook and Leutcher, 1996; Jelic et al., 1996; Kolev et al., 2002; Leutcher et al., 1993; Nobili et al., 1998; Pucci et al., 1997). Furthermore, it followed Klimesch and others' theoretical consideration that near EEG rhythms may overlap at their frequency borders (Babiloni et al., 2004b,c,d,e,f; 2005b,c; Klimesch, 1996; 1999; Klimesch et al., 1997; 1998).

Choice of fixed EEG bands did not account for individual alpha frequency (IAF) peak, defined as the frequency associated with the strongest EEG power at the extended alpha range (Klimesch, 1999). However, this may not affect the results, since most of the subjects had IAF peaks within alpha 1 band $(8-10.5 \mathrm{~Hz})$. In particular, mean IAF peak was $9.4 \mathrm{~Hz}( \pm 0.1$ standard error, SE) in Nold subjects, $9.2 \mathrm{~Hz}$ $( \pm 0.1 \mathrm{SE})$ in MCI subjects, and $8.5 \mathrm{~Hz}( \pm 0.1 \mathrm{SE})$ in mild $\mathrm{AD}$ subjects. Furthermore, IAF peak was used as a covariate for further statistics (Klimesch, 1999).

We could not use narrow frequency bands for beta 1 $(13-20 \mathrm{~Hz})$ and beta $2(20-30 \mathrm{~Hz})$, because of the variability of the beta peaks in the power spectra. Therefore, the LORETA results for the beta bands could suffer from the sensitivity limitations of EEG spectral analyses for large bands (Szava et al., 1994).

\subsection{Cortical source analysis of the EEG rhythms by LORETA}

As aforementioned, the popular LORETA technique was used for the EEG source analysis as provided at http://www. unizh.ch/keyinst/NewLORETA/LORETA01.htm (PascualMarqui et al., 1994, 1999, 2002). LORETA computed 3D linear solutions (LORETA solutions) for EEG inverse problem within a three-shell spherical head model including scalp, skull, and brain compartments. Brain compartment was restricted to the cortical gray matter/hippocampus of a head model co-registered to Talairach probability brain atlas and digitized at the Brain Imaging Center of the Montreal Neurologic Institute (Talairach and Tournoux, 1988). This compartment included 2394 voxels (7 mm resolution), each voxel containing an equivalent current dipole. LORETA is one EEG functional imaging technique belonging to a large family of linear inverse solution and tomographic procedures (Fuchs et al., 2001; Gross et al., 2003; PascualMarqui et al., 2002; Sekihara et al., 2005; Valdes et al., 1998), modeling 3D distributions of EEG sources with comparable performances. In our studies, we preferred to use LORETA for two reasons. Firstly, LORETA has been repeatedly used from data collected by low spatial sampling of 10-20 system (19 electrodes, Anderer et al., 2000; 2003; 2004; Babiloni et al., 2004a; Cincotti et al., 2004; Isotani et al., 2001; Kawasaki et al., 2004; Laufer and Pratt, 2003a,b; 
Mulert et al., 2001; Veiga et al., 2003; Winterer et al., 2001). Secondly, several investigation of EEG rhythms in physiological and pathological aging used LORETA, so the results of the present study could be put in a large framework of previous evidence (Anderer et al., 1998a,b; 2003; Babiloni et al., 2004a, 2005a; Cincotti et al., 2004a; Dierks et al., 2000; Goforth et al., 2004; Huang et al., 2002; Saletu et al., 2002). This was probably due to the fact that spatial smoothing of the LORETA solutions (resolution in centimeters) and its head template could reliably take into account the slight change in the cortical volume (resolution in millimeters) present in the mild stages of AD.

The LORETA solutions consisted of voxel spectral density of estimated z-current density values able to predict EEG spectral data at scalp electrodes. These solutions are reference free, in that one obtains the same LORETA source distribution for EEG data referenced to any reference electrode including common average. To enhance the topographical results, a 'spatial' normalization was obtained by normalizing the LORETA current density at each voxel with the LORETA power density averaged across all frequencies $(0.5-45 \mathrm{~Hz})$ and across all 2.394 voxels of the brain volume. After the normalization, the LORETA solutions lost the original physical dimension and were represented by an arbitrary unit scale. This procedure reduced inter-subjects variability and was used in previous our EEG study (Babiloni et al., 2004a; 2005a). The general procedure fitted the LORETA solutions in a Gaussian distribution and reduced inter-subject variability (Nuwer, 1988; Leuchter et al., 1993).

Solutions of the EEG inverse problem are underdetermined and ill-conditioned when the number of spatial samples (electrodes) is lower than that of the unknown samples (current density at each voxel). To account for that, the cortical LORETA solutions predicting scalp EEG spectral power density were regularized to estimate distributed rather than punctual EEG source patterns (Pascual-Marqui et al., 1994, 1999, 2002). Of note, LORETA package associated each LORETA solution with a Brodmann area. In line with the low spatial resolution of the LORETA technique, we used our MATLAB software to collapse the voxels of LORETA solutions at frontal, central, temporal, parietal, occipital, and 'limbic' (as defined in the original LORETA package; we used the brackets since, the 'limbic' LORETA sources can recovery only a part of the actual limbic rhythms) regions of the brain model coded into Talairach space. The Brodmann areas listed in Table 2 formed each of these regions of interest (ROIs). Of note, the same procedure were used in our previous studies (Babiloni et al., 2004a, 2005a). Finally, the main advantage of the regional analysis of LORETA solutions was that our modelling could disentangle rhythms of contiguous cortical areas. For example, the rhythms of the occipital source were disentangled with respect to those of the contiguous parietal and temporal sources etc. This was made possible by the fact that LORETA solves the
Table 2

Brodmann areas included in the cortical regions of interest (ROIs) of the present study

Loreta broadmann areas into the regions of interest (ROIs)

\begin{tabular}{ll}
\hline Frontal & $8,9,10,11,44,45,46,47$ \\
Central & $1,2,3,4,6$ \\
Parietal & $5,7,30,39,40,43$ \\
Temporal & $20,21,22,37,38,41,42$ \\
Occipital & $17,18,19$ \\
Limbic & $31,32,33,34,35,36$
\end{tabular}

LORETA solutions were collapsed in frontal, central, parietal, temporal, occipital, and limbic ROIs.

linear inverse problem by taking into account the wellknown effects of the head as a volume conductor.

\subsection{Statistical analysis of the LORETA solutions}

Regional normalized LORETA solutions were used as dependent variables for ANOVA analysis, using subjects' age, education and IAF peak as covariates. To test the present working hypothesis, ANOVA factors (levels) were Group (mild AD, MCI, Nold; independent variable), Band (delta, theta, alpha 1, alpha 2, beta 1, beta 2), and ROI (central, frontal, parietal, occipital, temporal, limbic). Mauchly's test evaluated the sphericity assumption. Correction of the degrees of freedom was made with the Greenhouse-Geisser procedure. Duncan test was used for post-hoc comparisons $(P<0.05)$. The planned post-hoc testing evaluated the prediction of progressive changes in magnitude of the LORETA solutions across Nold, MCI, and mild AD subjects. That prediction would be confirmed by the following LORETA patterns: Nold $>$ MCI $>$ mild AD and Nold $<$ MCI $<$ mild AD.

LORETA solutions showing statistically significant differences according to the LORETA pattern Nold $>$ MCI $>$ mild $\mathrm{AD}$ or Nold $<\mathrm{MCI}<$ mild $\mathrm{AD}$ were evaluated as linear and non-linear correlations with MMSE score in all subjects as a single group. The linear correlation was computed with Pearson test (Bonferroni corrected, $P<0.05$ ). The non-linear correlations were computed evaluating the coefficient of determination $r^{2}$ for exponential, logarithmic, and power functions. The $r^{2}$ value was computed with the following mathematical formula:

$r^{2}=1-(\mathrm{SSE} / \mathrm{SST})$

where

$\mathrm{SSE}=\sum\left(y_{\mathrm{i}}-¥_{\mathrm{i}}\right)$ and $\mathrm{SST}=\sum\left(y_{\mathrm{i}}^{2}\right)-\frac{\sum\left(y_{\mathrm{i}}\right)^{2}}{n}$

where $n$ is the number of samples (i.e. subjects), $y_{\mathrm{i}}$ is the real value and $¥_{i}$ is the approximated value calculated with the following formula:

$¥_{i}=c \ln x_{\mathrm{i}}+b$ for logarithmic functions ( $c, b$ constant $)$ 
$¥_{i}=c e^{\mathrm{bx}}$ for exponential functions ( $c, b$ constant)

$¥_{i}=c x_{\mathrm{i}}^{b}$ for power functions ( $c, b$ constant)

Finally, $r^{2}$ of the non-linear simple functions was compared with $r^{2}$ of the linear function, to evaluate the prevalence of linear or non-linear EEG correlations between regional LORETA solutions and MMSE score. Of note, the non linear correlations between MMSE and LORETA solutions were studied with simple non linear functions. The same non linear functions have been successfully used in our previous EEG study on physiological aging (Babiloni et al., 2005a). An interesting alternative approach for future investigations would have the use of general nonlinear coefficient $h 2$, which could deal with all types of nonlinear correlation (Lopes da Silva et al., 1989) and a deeper correlative analysis of EEG sources and neuropsychological variables other than the MMSE score.

\section{Results}

\subsection{Topography of the EEG cortical sources estimated by LORETA}

For illustrative purposes, Fig. 1 maps the grand average of the LORETA solutions (i.e. relative $z$-current density at cortical voxels) modeling the distributed EEG sources for delta, theta, alpha 1 , alpha 2 , beta 1 , and beta 2 bands in Nold, MCI, and mild AD groups. The Nold group presented alpha 1 sources with maximal values of the relative current density distributed in parieto-occipital regions. Delta, theta and alpha 2 sources had moderate relative current density values when compared to alpha 1 sources. Finally, beta 1 and beta 2 sources were characterized by lowest relative current density values. Compared to Nold group, mild AD group showed an increase of widespread delta sources, along with a dramatic reduction of parieto-occipital alpha 1 sources. With respect to Nold and mild AD groups, MCI group showed intermediate magnitude of delta and alpha 1 sources and greater magnitude of alpha 2 sources.

\subsection{Statistical analysis of the EEG cortical sources estimated by LORETA}

Fig. 2 shows mean regional LORETA solutions (distributed EEG sources) relative to a statistical ANOVA interaction $(F(50,11750)=5.4 ; \mathrm{MSe}=0.63 ; P<0.00001)$ among the factors Group (Nold, MCI, mild AD), Band (delta, theta, alpha 1 , alpha 2 , beta 1 , beta 2 ), and ROI (central, frontal, parietal, occipital, temporal, limbic). In the figure, LORETA solutions had the shape of EEG relative power spectra. Notably, profile and magnitude of these spectra in Nold, MCI, and mild AD groups differed in the diverse cortical regions, thus supporting the idea that scalp

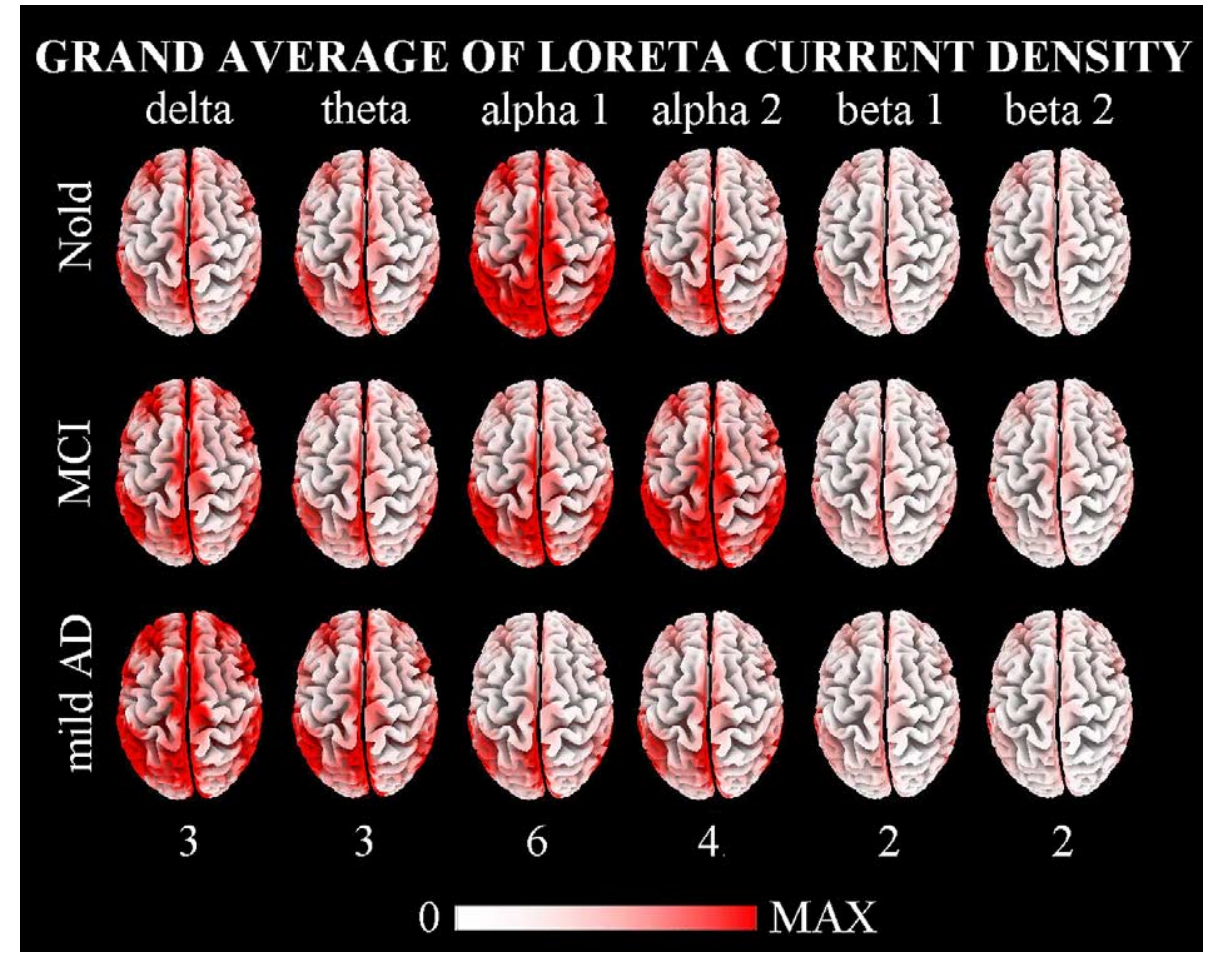

Fig. 1. Grand average of LORETA solutions (i.e. normalized relative current density at the cortical voxels) modeling the distributed EEG sources for delta, theta, alpha 1, alpha 2, beta 1, and beta 2 bands in Nold, MCI and mild AD groups. The left side of the maps (top view) corresponds to the left hemisphere. Legend: LORETA, low-resolution brain electromagnetic tomography. Color scale: all power estimates was scaled based on the averaged maximum value (i.e. alpha 1 power value of occipital region in Nold). The maximal value of power is reported under each column. 


\section{STATISTICAL ANOVA INTERACTION OF GROUP. BAND. ROI}

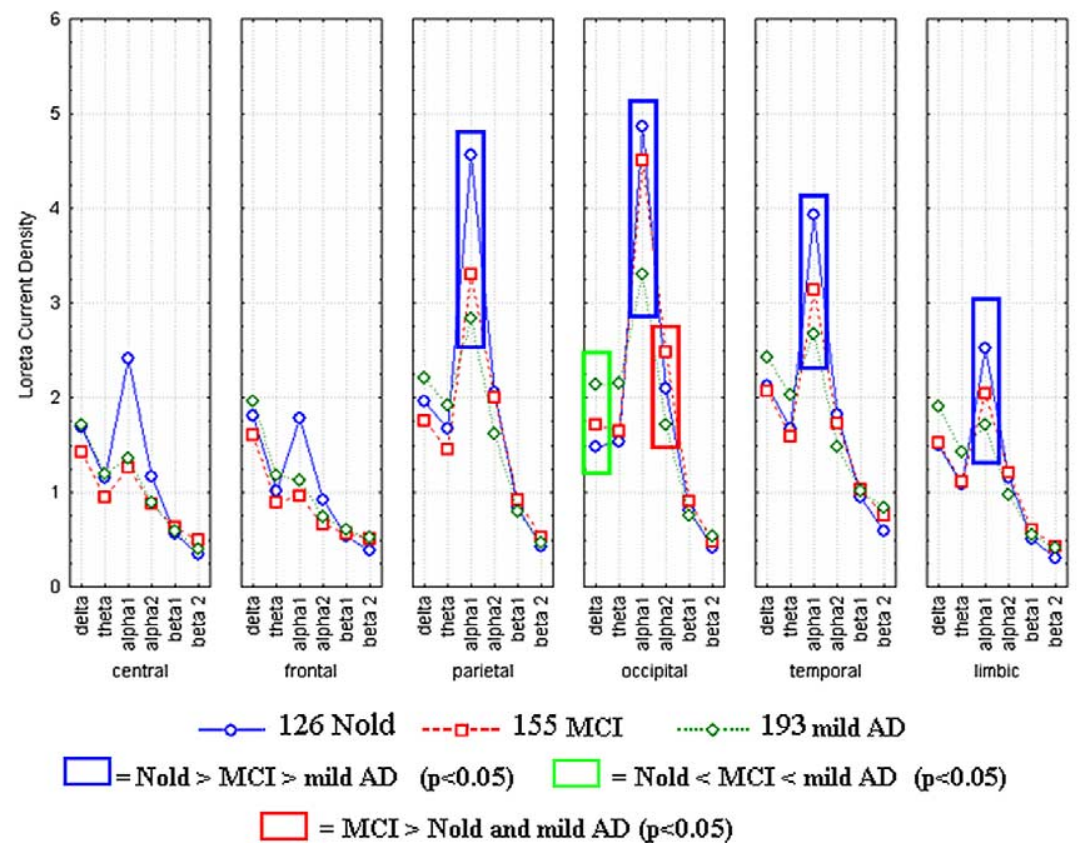

Fig. 2. Regional LORETA solutions (mean across subjects) relative to a statistical ANOVA interaction among the factors Group (Nold, MCI, mild AD), Band (delta, theta, alpha 1, alpha 2, beta 1, beta 2), and ROI (central, frontal, parietal, occipital, temporal, limbic). This ANOVA design used the normalized relative current density values at ROI level as a dependent variable. Subjects' age, education and individual alpha frequency peak (IAF) were used as covariates. Regional LORETA solutions modeled the EEG relative power spectra as revealed by a sort of 'virtual' intracranial macro-electrodes 'disposed' on the macrocortical regions of interest. Legend: the rectangles indicate the cortical regions and frequency bands in which LORETA solutions presented statistically significant different values with respect to the LORETA patterns: Nold $>$ MCI $>$ mild AD, Nold $<\mathrm{MCI}<$ mild $\mathrm{AD}$ and $\mathrm{MCI} \neq \mathrm{Nold}$ and mild $\mathrm{AD}(P<0.05$, planned Duncan post-hoc testing). See Methods for further details.

EEG rhythms are generated by a distributed pattern of cortical sources.

According to the working hypothesis, the planned Duncan post-hoc testing assessed the progressive differences in the regional LORETA solutions across the three groups, that is Nold $>$ MCI $>$ mild $\mathrm{AD}$ or Nold $<\mathrm{MCI}<$ mild $\mathrm{AD}$. In that line, parietal, occipital, temporal, and limbic alpha 1 sources showed stronger amplitude in Nold compared to MCI group $(P<0.01)$ and in MCI compared to mild AD group $(P<0.000008)$. On the contrary, occipital delta sources showed lower amplitude in Nold compared to MCI group $(P<0.04)$ and in MCI compared to mild AD group $(P<0.00006)$.

Magnitude values of these five EEG sources were correlated with MMSE score in all subjects as a single group (Pearson test; Bonferroni correction for five repetitions of the test gave the threshold $P<0.01$ to obtain the Bonferroni corrected $P<0.05$ ). Fig. 3 shows scatterplots between individual LORETA solutions and MMSE scores of the statistically significant correlations $(P<0.01)$. According to the first working hypothesis, MMSE score negatively correlated with occipital delta sources $(r=-0.18, P=0.00007)$ and positively correlated with parietal $(r=0.15, P=0.0009)$, occipital $(r=0.19$, $P=0.00003)$, temporal $(r=0.16, P=0.0005)$, and limbic $(r=0.18, P=0.00004)$ alpha 1 sources. We repeated the correlation analysis between MMSE score and the five EEG sources using Spearman test $(P<0.01)$. The results confirmed those obtained with Pearson test. Indeed, the MMSE score negatively correlated with occipital delta sources $(r=-0.13, P=0.004)$ and positively correlated with parietal $(r=0.13, P=0.003)$, occipital $(r=0.15$, $P=0.001)$, temporal $(r=0.13, P=0.004)$, and 'limbic' $(r=0.14, P=0.002)$ alpha 1 sources. Remarkably, we preferred correlate MMSE score and EEG source in all subjects as a single group, since the range of the MMSE score within the single groups was very low.

Table 3 reports coefficient of determination $r^{2}$ between individual regional LORETA solutions and MMSE score in all subjects considered as a single group. The $r^{2}$ value is reported for the linear (Pearson), exponential, logarithmic, and power functions. In general, $r^{2}$ values for linear, exponential, logarithmic, and power functions were quite similar. Of note, non linear functions included only simple functions such as logarithmic, exponential and power ones, since the scatterplot distribution of the data discouraged complex non linear functions such as polynomial ones.

\subsection{Control analyses}

As a first control analysis, the planned Duncan post-hoc testing assessed the differences of the regional LORETA 


\section{SCATTERPLOT BETWEEN MMSE AND LORETA CURRENT DENSITY}
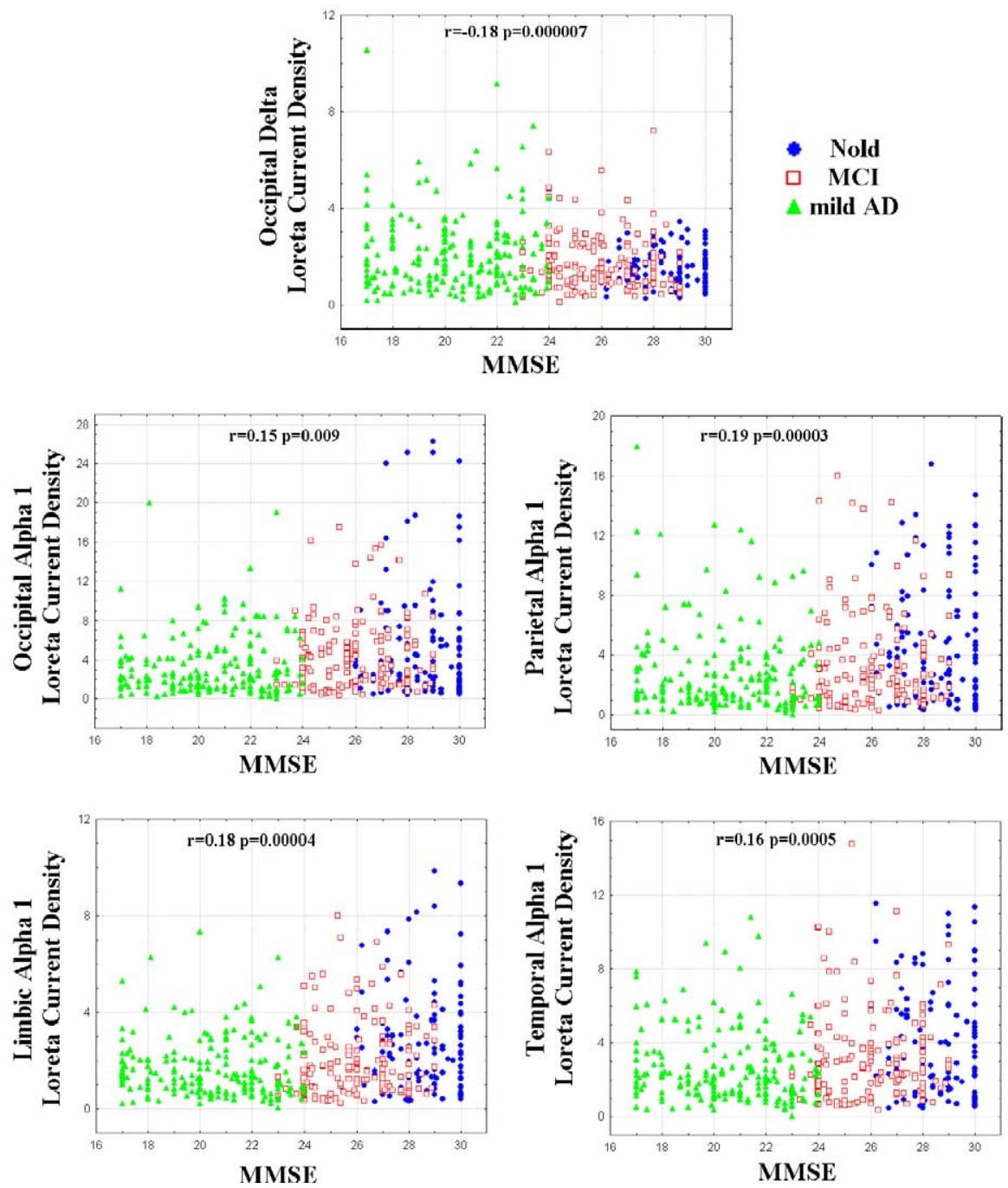

Fig. 3. Scatterplots between the individual regional LORETA solutions and the MMSE score in all Nold, MCI, and mild AD subjects as a single group. These solutions refer to the EEG sources showing a statistically significant progression of the magnitude values across Nold, MCI, and mild AD, namely occipital delta source as well as parietal, occipital, temporal and limbic alpha 1 sources. The $\mathrm{r}$ and $\mathrm{p}$ value between the individual regional LORETA solutions and the MMSE score are reported within the diagrams.

solutions characterizing the MCI group with respect to the Nold and mild AD groups, namely the source patter $\mathrm{MCI} \neq$ Nold and mild AD. In that line, the occipital alpha 2 sources showed stronger amplitude in MCI group than in Nold $(P<0.0001)$ and mild AD $(P<0.0001)$ groups. As a note, the Duncan post-hoc also unveiled that: (i) the delta sources in parietal, temporal and limbic areas showed stronger amplitude in AD group compared than in Nold $(P<0.02)$ and MCI $(P<0.0005)$ groups; (ii) the theta sources in parietal, occipital, temporal and limbic areas showed stronger amplitude in $\mathrm{AD}$ group than in Nold $(P<0.02)$ and MCI $(P<0.002)$ groups. Finally, the Duncan post hoc test showed that the amplitude of beta 1 and beta 2 sources did not differ among Nold, MCI and mild $\mathrm{AD}$ subjects. Of note, the very low amplitude of the beta sources indicated that the EEG recordings were not contaminated by muscular and instrumental artifacts. Indeed, the presence of these artifacts would have increased the amplitude of the beta LORETA sources.

As previously mentioned, age, education and gender significantly differed among Nold, MCI, and mild AD. For this reason, a second control ANOVA analysis was necessary to assure that the above described LORETA source differences among Nold, MCI, and mild AD groups were not due to age, education, and gender. We considered sub-groups of Nold $(N=50)$, MCI $(N=50)$ and mild AD $(N=50)$ subjects, having practically equal age, education, and ratios of gender. Table 4 reports the means of personal and neurophysiological parameters of these three sub-groups. The LORETA solutions were used as a dependent variable. The ANOVA factors (levels) were Group (Nold, MCI, mild AD; independent variable), Band 
Table 3

Correlation (coefficient of determination $r^{2}$ ) between individual regional LORETA solutions and Mini Mental State Evaluation (MMSE) score in all Nold, MCI and mild AD subjects considered as a single group

Correlation between LORETA current density and MMSE score (coefficient of determination $r^{2}$ )

\begin{tabular}{lllll}
\hline & Linear & Logarithmic & Exponential & Power \\
\hline $\begin{array}{l}\text { Occipital } \\
\text { delta source }\end{array}$ & 0.03 & 0.03 & 0.01 & 0.01 \\
$\begin{array}{l}\text { Parietal } \\
\text { alpha 1 }\end{array}$ & 0.02 & 0.02 & 0.02 & 0.02 \\
$\begin{array}{l}\text { source } \\
\text { Occipital } \\
\text { alpha 1 }\end{array}$ & 0.04 & 0.04 & 0.03 & 0.2 \\
$\begin{array}{l}\text { source } \\
\text { Temporal } \\
\text { alpha 1 } \\
\text { source }\end{array}$ & 0.02 & 0.02 & 0.01 & 0.01 \\
$\begin{array}{l}\text { Limbic } \\
\text { alpha 1 } \\
\text { source }\end{array}$ & 0.03 & 0.03 & 0.02 & 0.02 \\
\hline
\end{tabular}

The $r^{2}$ value is reported for linear (Pearson test), exponential, logarithmic, and power function. Of note, only the regional LORETA solutions showing the progressive differences across the three groups (Nold $>$ MCI $>$ mild AD or Nold $<\mathrm{MCI}<$ mild $\mathrm{AD}$ ) were considered for that analysis.

(delta, theta, alpha 1 , alpha 2 , beta 1 , beta 2 ), and ROI (central, frontal, parietal, occipital, temporal, limbic). There was a statistical interaction $(F(50,3675)=3.55 ; \mathrm{MSe}=0.58$; $P=0.0001$ ) among factors Group, Band and ROI (see Fig. 4). Notably, profile and magnitude of these LORETA sources in Nold, MCI, and mild AD sub-groups were similar compared to those of the larger three groups with age, education and gender bias. According to the statistical results obtained in the full groups, the planned Duncan posthoc testing assessed the progressive differences in the regional LORETA solutions across the three groups, that is Nold $>$ MCI $>$ mild AD or Nold $<$ MCI $<$ mild AD. In that line, parietal, occipital, temporal alpha 1 sources showed stronger amplitude in Nold compared to MCI group $(P<0.0001)$ and in MCI compared to mild AD group $(P<0.004)$. On the contrary, occipital delta sources showed lower amplitude in Nold compared to MCI group $(P<0.02)$ and in MCI compared to mild AD group $(P<0.00007)$. Furthermore, the planned Duncan post-hoc testing assessed

Table 4

Demographic and neuropsychological data of interest of normal aging (Nold), mild cognitive impairment (MCI) and mild Alzheimer's disease (AD) subjects

\begin{tabular}{llll}
\hline & Nold & MCI & Mild AD \\
\hline $\mathrm{N}$ & 50 & 50 & 50 \\
Age (years) & $72.1( \pm 0.9 \mathrm{SE})$ & $72.1( \pm 0.6 \mathrm{SE})$ & $72( \pm 1.1 \mathrm{SE})$ \\
Gender $(\mathrm{F} / \mathrm{M})$ & $28 / 22$ & $28 / 22$ & $28 / 22$ \\
MMSE & $27.8( \pm 0.2 \mathrm{SE})$ & $25.4( \pm 0.4 \mathrm{SE})$ & $20.9( \pm 0.4 \mathrm{SE})$ \\
Education & $8.1( \pm 0.4 \mathrm{SE})$ & $8.1( \pm 0.6 \mathrm{SE})$ & $8.1( \pm 0.6 \mathrm{SE})$ \\
(years) & & & \\
\hline
\end{tabular}

The number of subjects was 50 for each group, having practically equal age, education and ratios of gender. the differences of the regional LORETA solutions characterizing the MCI group with respect to the Nold and mild $\mathrm{AD}$ groups, namely the source pattern $\mathrm{MCI} \neq$ Nold and mild AD. In that line, the occipital alpha 2 sources showed stronger amplitude in MCI group than in Nold $(P<0.05)$ and mild AD $(P<0.0001)$ groups. The Duncan post-hoc also unveiled that: (i) the delta sources in frontal, parietal, temporal and limbic areas showed stronger amplitude in AD group compared than in Nold $(P<0.03)$ and MCI $(P<0.0001)$ groups; (ii) the theta sources in parietal, occipital, temporal and limbic areas showed stronger amplitude in $\mathrm{AD}$ group compared than in Nold $(P<0.02)$ and MCI $(P<0.003)$ groups. This control ANOVA analysis fully confirmed the results obtained with the larger groups. Therefore, the LORETA source differences obtained in the full groups were not due to age, education, and gender.

Furthermore, two control ANOVA analyses were performed to assure that the above described LORETA source differences among Nold, MCI, and mild AD groups were not due to extremely large number of subjects. We considered two sub-groups of Nold, $\mathrm{MCI}$ and mild $\mathrm{AD}$ subjects: the sub-group A (63 Nold, $78 \mathrm{MCI}, 97$ mild AD) and the sub-group B (63 Nold, 77 MCI, 96 mild AD). The LORETA solutions were used as a dependent variable. The ANOVA factors (levels) were Group (Nold, MCI, mild AD; independent variable), Band (delta, theta, alpha 1, alpha 2, beta 1, beta 2), and ROI (central, frontal, parietal, occipital, temporal, limbic). For both sub-groups, there was a statistical interaction among factors Group, Band and ROI $(P<0.0001)$. According to the statistical results obtained in the full groups, the planned Duncan post-hoc testing assessed the progressive differences in the regional LORETA solutions across the three groups, that is Nold $>$ $\mathrm{MCI}>$ mild $\mathrm{AD}$ or Nold $<\mathrm{MCI}<$ mild $\mathrm{AD}$. In that line, for both sub-groups, parietal, occipital, temporal, limbic alpha 1 sources showed stronger amplitude in Nold compared to MCI group $(\mathrm{p}<0.04)$ and in MCI compared to mild AD group ( $\mathrm{p}<0.05)$. On the contrary, the occipital delta sources showed lower amplitude in Nold compared to MCI group $(P<0.03)$ and in MCI compared to mild AD group $(P<0.007)$ only for sub-group B. For the sub-group A, the occipital delta sources showed lower amplitude in Nold and MCI compared to mild AD group $(P<0.02)$. Furthermore, the planned Duncan post-hoc test assessed the differences of the regional LORETA solutions characterizing the MCI group with respect to the Nold and mild $\mathrm{AD}$ groups, namely the source pattern $\mathrm{MCI} \neq$ Nold and mild AD. In that vein, the occipital alpha 2 sources showed stronger amplitude in MCI group than in Nold $(P<0.00001)$ and mild $\mathrm{AD}(P<0.0001)$ groups only for sub-groups $\mathrm{A}$. This control ANOVA analysis globally (alpha 1 and delta) confirmed the results obtained with the full groups.

To cross-validate the LORETA differences among Nold, $\mathrm{MCI}$, and mild $\mathrm{AD}$ groups, the analysis was directly repeated on the EEG data used as an input for the LORETA analysis. For this analysis, we considered the above 


\section{STATISTICAL ANOVA INTERACTION OF GROUP. BAND. ROI}

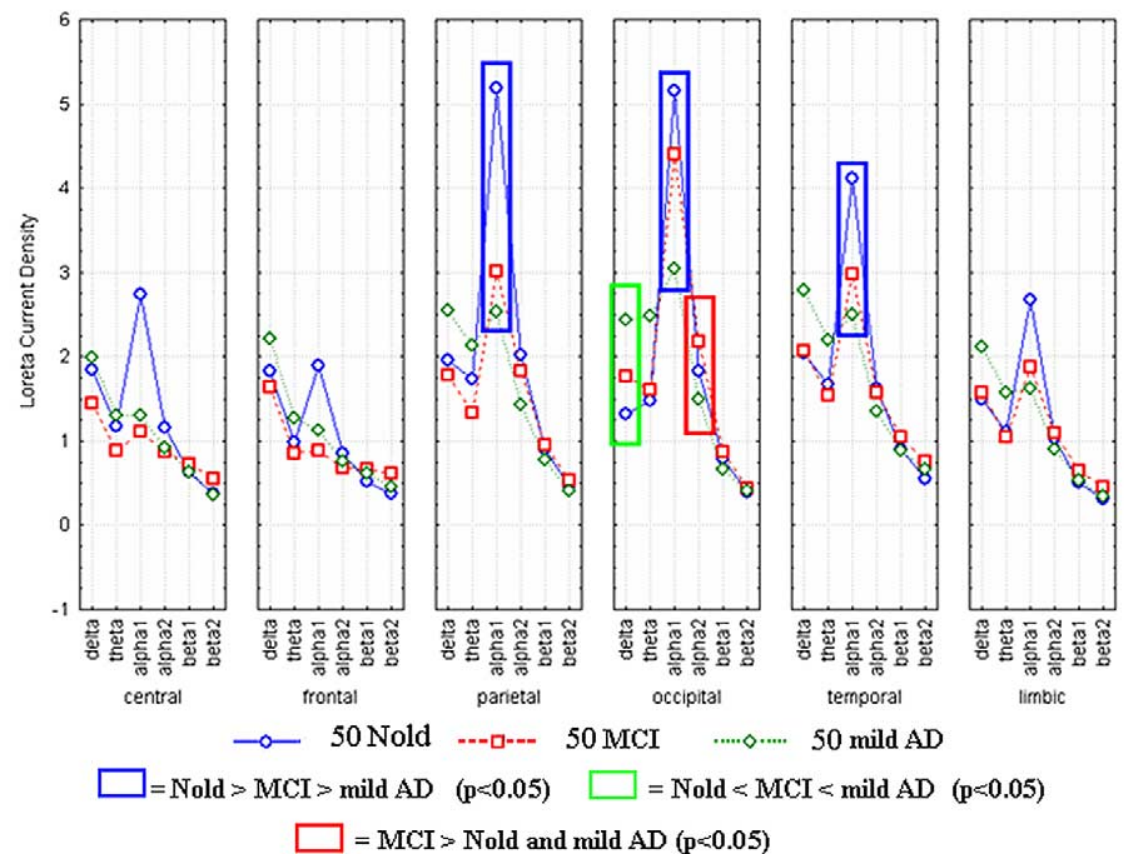

Fig. 4. Regional LORETA solutions (mean across subjects) relative to a statistical ANOVA interaction among the factors Group (Nold, MCI, mild AD), Band (delta, theta, alpha 1, alpha 2, beta 1, beta 2), and ROI (central, frontal, parietal, occipital, temporal, limbic). This ANOVA design used the normalized relative current density values at ROI level as a dependent variable. Subjects' age, education and individual alpha frequency peak (IAF) were used as covariates. The number of subjects was 50 for each group, having practically equal age, education and ratios of gender. Legend: the rectangles indicate the cortical regions and frequency bands in which LORETA solutions presented statistically significant different values with respect to the LORETA patterns: Nold $>$ MCI $>$ mild AD, Nold $<\mathrm{MCI}<$ mild $\mathrm{AD}$ and $\mathrm{MCI} \neq$ Nold and mild $\mathrm{AD}(P<0.05$, planned Duncan post-hoc testing $)$.

described subgroups of Nold $(N=50)$, MCI $(N=50)$ and mild $\mathrm{AD}(N=50)$ subjects. The same frequency bands of interest of the LORETA analysis were considered, namely delta $(2-4 \mathrm{~Hz})$, theta $(4-8 \mathrm{~Hz})$, alpha $1(8-10.5 \mathrm{~Hz})$, alpha 2 $(10.5-13 \mathrm{~Hz})$, beta $1(13-20 \mathrm{~Hz})$, and beta $2(20-30 \mathrm{~Hz})$. Five ROIs were considered. These ROIs included, respectively: (i) $\mathrm{C} 3, \mathrm{Cz}$ and $\mathrm{C} 4$ electrodes for the central region, (ii) $\mathrm{F} 3, \mathrm{Fz}$ and $\mathrm{F} 4$ electrodes for the frontal region, (iii) $\mathrm{P} 3, \mathrm{Pz}$ and $\mathrm{P} 4$ electrodes for the parietal region, (iv) $\mathrm{O} 1, \mathrm{O} 2$ electrodes for the occipital region, (v) T3, T4, T5, T6 for the temporal region. Compared to the LORETA results, the 'limbic' region was excluded due to its deep location. The same kind of normalization of the LORETA solutions was used for the EEG spectral solutions of this control analysis. The EEG spectral power density at each electrode was normalized to the EEG spectral power density averaged across all frequencies $(0.5-45 \mathrm{~Hz})$ and across all electrodes. The values of normalized spectral power density of the electrodes belonging to the same ROI were averaged at each of the 6 frequency bands of interest.

The results of the control data analysis were used as inputs for an ANOVA analysis. The values of the normalized, regional spectral power density served as a dependent variable. The ANOVA factors (levels) were Group (Nold, MCI, mild AD), Band (delta, theta, alpha 1, alpha 2, beta 1 , beta 2 ), and ROI (central, frontal, parietal, occipital, temporal). Subjects' age, education and IAF were used as covariates. This ANOVA design showed a statistical interaction $(F(40,2940)=7.41 ; \mathrm{MSe}=0.92$; $P<0.0001$ ) between factors Group, Band and ROI (see Fig. 5). According to the statistical results obtained in the LORETA sources analysis, the planned Duncan post-hoc testing assessed the progressive differences in the normalized regional spectral power density across the three groups, that is Nold $>$ MCI $>$ mild AD or Nold $<$ $\mathrm{MCI}<$ mild $\mathrm{AD}$. In that line, parietal, occipital, temporal alpha 1 sources showed stronger amplitude in Nold compared to MCI group $(P<0.003)$ and in MCI compared to mild AD group $(P<0.0009)$. On the contrary, occipital delta sources showed lower amplitude in Nold compared to MCI group $(P<0.03)$ and in MCI compared to mild AD group $(P<0.004)$. Furthermore, the planned Duncan post-hoc testing assessed the differences of the normalized regional spectral power density characterizing the MCI group with respect to the Nold and mild $\mathrm{AD}$ groups, namely the source pattern MCI $\neq$ Nold and mild AD. In this vein, the occipital alpha 2 sources showed stronger amplitude in MCI group than in Nold $(P<0.02)$ and mild AD $(P<0.000001)$ groups. On the whole, these ANOVA results confirmed the differences among Nold, MCI and mild AD in line with the results of the LORETA analysis. 


\section{STATISTICAL ANOVA INTERACTION OF GROUP, BAND, ROI}

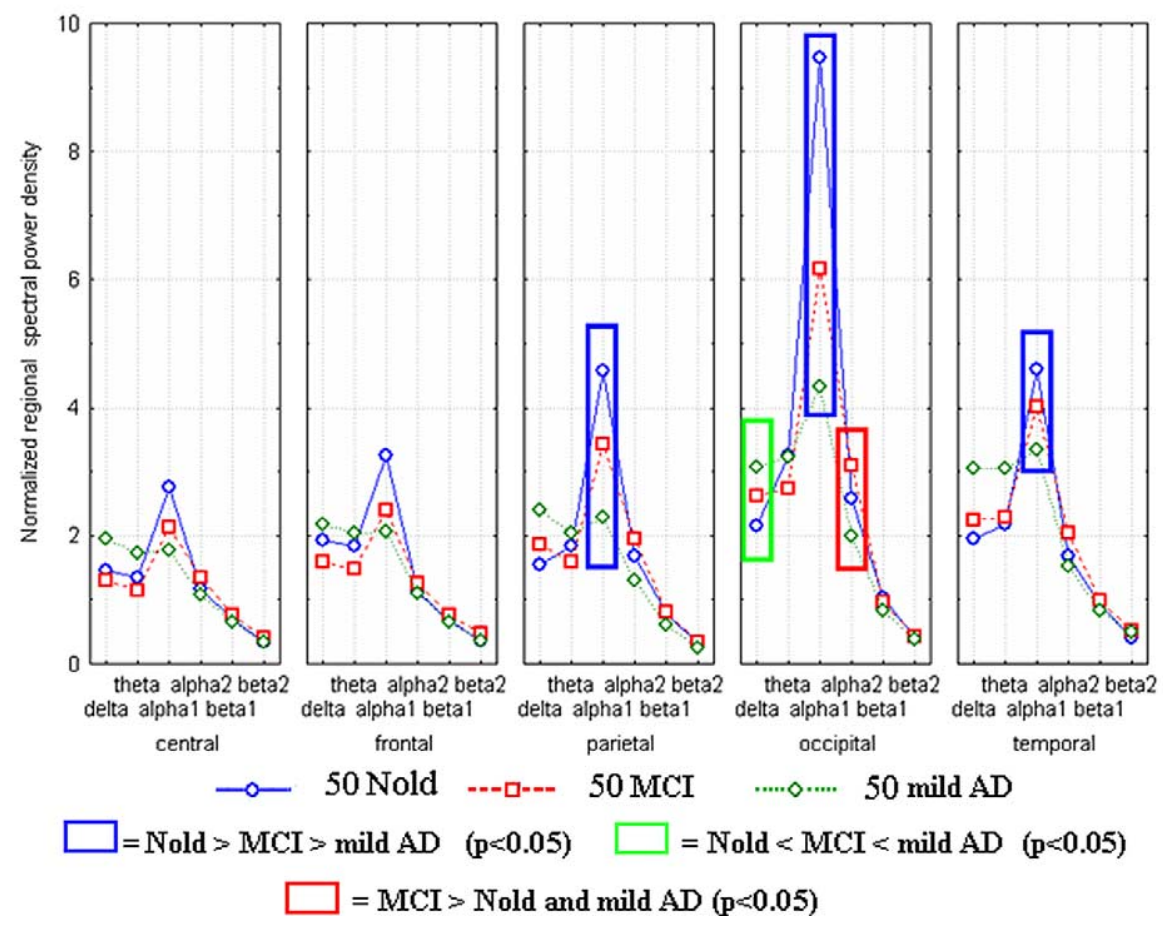

Fig. 5. Normalized regional EEG spectral power density relative to a statistical ANOVA interaction among the factors the factors Group (Nold, MCI, mild AD), Band (delta, theta, alpha 1, alpha 2, beta 1, beta 2), and ROI (central, frontal, parietal, occipital, temporal). This control ANOVA design was focused on the EEG data used as an input for the LORETA analysis, in order to cross validate the LORETA solutions. The ANOVA design used the normalized regional EEG spectral power density as a dependent variable. Subjects' age, education and individual alpha frequency peak (IAF) were used as covariates. Legend: the rectangles indicate the cortical regions and frequency bands in which LORETA solutions presented statistically significant different values with respect to the LORETA patterns: Nold $>\mathrm{MCI}>$ mild $\mathrm{AD}$, Nold $<\mathrm{MCI}<$ mild $\mathrm{AD}$ and $\mathrm{MCI} \neq$ Nold and mild $\mathrm{AD}(P<0.05$, planned Duncan post-hoc testing).

\section{Discussion}

\subsection{Cortical sources of EEG rhythms change as a function of the global cognitive level}

In the present study, low-band $(8-10.5 \mathrm{~Hz})$ alpha sources in parietal, occipital, temporal, and limbic areas had an intermediate magnitude in MCI subjects when compared to mild AD and Nold subjects. Furthermore, magnitude of these five EEG sources showed positive linear and nonlinear (i.e. correlations with MMSE score (global cognitive level) across all Nold, MCI, and mild AD subjects as a single group. These results suggest that the global neurophysiological variables (posterior cortical rhythmicity) were linearly and not linearly correlated with global clinical and cognitive status (MMSE score) across the shadow region between physiological and pathological aging. In this sense, they support the hypothesis of a transition from MCI to $\mathrm{AD}$ having linear and non-linear components. However, it should be remarked that, even if statistically significant (up to $P=0.0005$ ), the absolute values of the linear and non linear correlations were relatively low (i.e. $r=0.15-0.19$ ). Therefore, the present results indicate that focusing on dual relationships between a single EEG cortical source and pathological aging may be insufficient to model the effects of pathological aging on cortical EEG rhythms. This is true even if both linear and non linear trends are taken into account by correlative approach. It can be speculated that a so high variance of the correlative data might be better explained by considering the complex relationships among several EEG cortical sources and the global clinical and cognitive status. As a logical consequence, this phenomenon should be accounted for using not only linear (i.e. logistics regression) but also non-linear (i.e. artificial neural networks) predictors. Of note, the present results cannot be explained by invoking neither the effects of psychoactive drugs possibility or that our MCI subjects had early mild AD, vascular and/or extrapyramidal co-morbidity. Indeed, special attention was paid to these aspects during clinical recruitment (see Methods).

The present results extend in spatial detail previous EEG evidence showing a decrease of alpha power in MCI compared to normal subjects (Frodl et al., 2002; Grunwald et al., 2001; Huang et al., 2000; Jelic et al., 1996; 2000). Furthermore, they complement previous evidence of early atrophy signs in limbic, precuneus, and posterior cingulate areas of MCI subjects (Baron et al., 2001; Callen et al., 2001). Finally, the present results complement previous evidence of reduced $\mathrm{rCBF}$ and/or glucose metabolism in temporo-parietal association areas, posterior cingulate, 
and hippocampus in MCI subjects, which were associated with a higher risk of progressive cognitive decline (Arnaiz et al., 2001; Huang et al., 2002; Johnson et al., 1998; Kitayama et al., 2001; Minoshima et al., 1994; Okamura et al., 2002; Rodriguez et al., 2000).

From a physiological point of view, alpha rhythms are mainly modulated by thalamo-cortical and cortico-cortical interactions (Brunia, 1999; Pfurtscheller and Lopes da Silva, 1999; Steriade and Llinas, 1988). Within extended alpha band $(8-13 \mathrm{~Hz})$, low-band alpha would be mainly related to subject's global attentional readiness, whereas high-band alpha would reflect the engagement of specific neural channels for the elaboration of sensorimotor or semantic information (Klimesch, 1996; Klimesch et al., 1997; 1998). At rest, the voltage of the alpha rhythms would be inversely correlated with the cortical excitability and level of attention processes depending on the novelty and importance of the stimulus. For this reason, it has been suggested that the amplitude of alpha rhythms and corresponding cortical excitability reflect at least in part the time-varying inputs of forebrain cholinergic pathways (Ricceri et al., 2004). These concepts constitute an important element of the current theory on the functional meaning of alpha rhythms.

Keeping in mind the mentioned concepts, a tentative speculation to explain the present results can be as follows. In our MCI subjects, magnitude decrease of posterior lowband alpha sources may be related to an initial selective impairment of cholinergic basal forebrain, which might induce sustained increase of the excitatory activity in cholinergic brain-stem pathway (Kobayashi and Tadashi, 2002; Sarter and Bruno, 1997; 1998). As a consequence, the thalamocortical excitability would desynchronize resting alpha rhythms (Muzur et al., 2002) and would enhance cortical excitability in AD patients (Alagona et al., 2001; Babiloni et al., 2000; 2005b; Ferri et al., 1996; Ferreri et al., 2003; Pennisi et al., 2002). In line with this explanation, previous studies have shown that resting rhythms including alpha were lowered by experimental damage to the cholinergic pathways stemming from basal forebrain (Holschneider et al., 1998; Mesulam, 2004). This pattern is consistent with what observed in mild $\mathrm{AD}$, a disease deeply affecting that cerebral region (Babiloni et al., 2004a; Dierks et al., 1993; 2000; Huang et al., 2000; Moretti et al., 2004; Rodriguez et al., 1999a,b). Furthermore, cholinergic basal forebrain was more structurally impaired in $\mathrm{AD}$ responders than non responders to treatment with cholinesterase inhibitors (Tanaka et al., 2003). Conversely, brainstem cholinergic innervations of the thalamus were found to be relatively spared in AD patients (Geula and Mesulam, 1989; 1996; 1999; Mash et al., 1985; Mesulam, 2004).

In our MCI group, the alpha findings paralleled those in occipital delta $(2-4 \mathrm{~Hz})$, which had an intermediate magnitude compared to mild $\mathrm{AD}$ and Nold subjects. Furthermore, magnitude of these EEG sources showed negative linear and non-linear correlations with MMSE score (global cognition) across all subjects. These results are compatible with previous EEG evidence showing increased slow rhythms in MCI compared to normal controls (Grunwald et al., 2001; Jelic et al., 2000; Prichep et al., 1994; Wolf et al., 2003). Furthermore, previous evidence have shown that the increase of slow EEG rhythms in AD is secondary to progressive cortical hypoperfusion (Brenner et al., 1986; Dossi et al., 1992; Kwa et al., 1993; Niedermeyer, 1997; Nobili et al., 1998; Passero et al., 1995; Rae-Grant et al., 1987; Stigsby et al., 1981; Steriade et al., 1994; Rodriguez et al., 1999a; Young, 1987).

From a physiological viewpoint, delta rhythms have been intensively studied during slow wave sleep. These rhythms are then replaced by fast (beta and gamma) cortical oscillations induced by the depolarizing effects of mesopontine cholinergic neurons acting on thalamocortical neurons and by the depolarizing effects of nucleus basalis cholinergic neurons acting on cortical neurons (Steriade, 2003). Therefore, it can be speculated that the increment of delta oscillations in MCI and AD subjects might be related to loss of hippocampal and posterior cortical neurons, which are impinged by cholinergic inputs. Indeed, it has been demonstrated that early degeneration in mesial temporal cortex of MCI and AD subjects can affect functional connectivity between hippocampal formation and temporoparietal cortex (Killiany et al., 1993). Furthermore, a bilateral reduction of gray matter volume in the hippocampal formation and entorhinal cortex of AD subjects was correlated with an increment of delta rhythms in posterior cortex (Fernandez et al., 2003).

In the present study, the theta sources in parietal, occipital, temporal and limbic areas had a stronger magnitude in mild AD subjects than MCI and Nold subjects. These results extend in spatial detail previous EEG evidence showing an increase of theta power in mild AD compared to normal subjects (Coben et al., 1983; Huang et al., 2000; Mattia et al., 2003; Ponomareva et al., 2003). This might be secondary to an impairment of cholinergic systems. A recent study in elderly subjects has shown enhancement of theta rhythm and decline of cognitive performance after the administration of a cholinergic antagonist (Osipova et al., 2003). In this vein, theta rhythm decreases in $A D$ subjects after cholinergic therapy (Adler et al., 2001, 2004; Brassen and Adler, 2003). However, at the end of this part of the discussion, it should be remarked that abnormal EEG rhythms can be observed not only in people with pathological aging but also in other kinds of neurologic disorders not clearly related to an impairment of the cholinergic systems (Priori et al., 2004). Therefore, the specific relationships between cortical EEG rhythms and AD should be further explored in future studies with several kinds of neurological disorders including vascular and frontotemporal dementias (Babiloni et al., 2004a). 


\subsection{Peculiar modulation of EEG sources in MCI subjects}

At first glance, we were surprised by the level of highband alpha source $(10.5-13 \mathrm{~Hz})$ in MCI when compared to the other control groups, in line with previous evidence obtained with a spatial average across the scalp of EEG power spectrum in a very initial stage of $\mathrm{AD}$ (Rodriguez et al., 1999b). It did not depend on the IAF peak, since the vast majority of our subjects had IAF peak within low-band alpha range $(8-10.5 \mathrm{~Hz})$.

An emerging feature of thalamo-cortical and corticocortical pathways is that the frequency of alpha oscillations is negatively correlated with their amplitude (Klimesch, 1996; Klimesch et al., 1997; Adler and Brassen, 2001; Klimesch, 1999; Nunez et al., 2001; Pfurtscheller and Lopes da Sarter and Bruno, 1997). Since the amplitude of the oscillations is proportional to the number of synchronously active neural elements (Fernandez et al., 2003), slowly oscillating cell assemblies comprise more synchronized neurons than fast oscillating cells (Singer, 1993). This might be due to the interplay of inter-neurons and coherently activated neurons (Lopes da Silva et al., 1976; Pfurtscheller and Lopes da Silva, 1999). Therefore, the enhanced high-band alpha of MCI subjects might be mediated by a decreasing number of synchronizing inter-neurons in the target cortical modules (Tononi et al., 1994). Future research should test if high-band alpha rhythms predict the cognitive decline in MCI. Indeed, not all MCI patients deteriorate over time (Bennett et al., 2002; Larrieu et al., 2002).

\subsection{Conclusions}

The results of the present study showed that cortical sources of EEG rhythms changed across Nold, MCI, and mild $\mathrm{AD}$ subjects, as a function of the global cognitive level. This was true for occipital delta and alpha 1 sources in parietal, occipital, temporal, and limbic areas, which had an intermediate magnitude in MCI subjects compared to mild $\mathrm{AD}$ and Nold subjects and were correlated with MMSE score across all subjects. The present results prompt future studies on the predictive value of cortical EEG rhythms in the early discrimination of MCI subjects who will convert to AD. This interesting issue could be addressed to by a proper longitudinal study. MCI subjects should be divided into 'converted' and 'stable' sub-groups, according to final outcome as revealed by follow up after about 5 years (i.e. the period needed for conversion of all MCI subjects fated to decline over time based on the mentioned literature). This study should demonstrate that the amplitude of EEG source at baseline measurement was different between MCI converted and MCI stable. Furthermore, baseline values of EEG sources in individual MCI subjects should be successfully used as an input by linear (i.e. logistics regression) and non-linear (i.e. artificial neural networks) predictors of conversion to dementia. These intriguing research perspectives are the sign of the heuristic value of the present findings. However, apart of clinical perspectives, the present findings have an intrinsic value for clinical neurophysiology. They provided further functional data from a large aged population to support 'transitional' hypothesis of a shadow zone across normality, pre-clinical stage of dementia (MCI), and mild AD.

\section{Acknowledgements}

We thank Ms Gabriella Busonero, Dr Andrea Cassarino, Ms Matilde Ercolani, Ms Rita Fini, Dr Massimo Gennarelli, Dr Nicola Girtler, Dr Simone Pocaterra, and Dr Katiuscia Sosta for their precious help in the development of the present study. We thank also Prof. Fabrizio Eusebi for his continuous support. The research was granted by Foundation Telethon Onlus (project EC0985)

\section{References}

Adler G, Brassen S. Short-term rivastigmine treatment reduces EEG slowwave power in Alzheimer patients. Neuropsychobiology 2001;43(4): 273-6.

Adler G, Brassen S, Chwalek K, Dieter B, Teufel M. Prediction of treatment response to rivastigmine in Alzheimer's dementia. J Neurol Neurosurg Psychiatry 2004;75(2):292-4.

Alagona G, Bella R, Ferri R, Carnemolla A, Pappalardo A, Costanzo E, Pennisi G. Transcranial magnetic stimulation in Alzheimer disease: motor cortex excitability and cognitive severity. Neurosci Lett 2001; 314(1-2):57-60.

Albert M, Smith LA, Scherr PA, Taylor JO, Evans DA, Funkestein HH. Use of brief cognitive test to identify individuals in the community with clinically diagnosed Alzheimer's disease. Int J Neurosci 1991;57: 167-78.

Anderer P, Pascual-Marqui RD, Semlitsch HV, Saletu B. Differential effects of normal aging on sources of standard N1, target N1 and target P300 auditory event-related brain potentials revealed by low resolution electromagnetic tomography (LORETA). Electroencephalogr Clin Neurophysiol 1998a;108(2):160-74.

Anderer P, Saletu B, Semlitsch HV, Pascual-Marqui RD. Electrical sources of P300 event-related brain potentials revealed by low resolution electromagnetic tomography. 2. Effects of nootropic therapy in ageassociated memory impairment. Neuropsychobiology 1998b;37(1): 28-35.

Anderer P, Saletu B, Pascual-Marqui RD. Effect of the 5-HT(1A) partial agonist buspirone on regional brain electrical activity in man: a functional neuroimaging study using low-resolution electromagnetic tomography (LORETA). Psychiatry Res 2000;100(2):81-96.

Anderer P, Saletu B, Semlitsch HV, Pascual-Marqui RD. Non-invasive localization of P300 sources in normal aging and age-associated memory impairment. Neurobiol Aging 2003;24(3):463-79.

Anderer P, Saletu B, Saletu-Zyhlarz G, Gruber D, Metka M, Huber J, Pascual-Marqui RD. Brain regions activated during an auditory discrimination task in insomniac postmenopausal patients before and after hormone replacement therapy: low-resolution brain electromagnetic tomography applied to event-related potentials. Neuropsychobiology 2004;49(3):134-53.

Arnaiz E, Almkvist O. Neuropsychological features of mild cognitive impairment and preclinical Alzheimer's disease. Acta Neurol Scand 2003; 107:34-41. 
Arnaiz E, Jelic V, Almkvist O, Wahlund LO, Winblad B, Valind S, Nordberg A. Impaired cerebral glucose metabolism and cognitive functioning predict deterioration in mild cognitive impairment. NeuroReport 2001;12(4):851-5.

Babiloni C, Babiloni F, Carducci F, Cincotti F, Del Percio C, De Pino G, Maestrini S, Priori A, Tisei P, Zanetti O, Rossini PM. Movementrelated electroencephalographic reactivity in Alzheimer disease. Neuroimage 2000;12(2):139-46.

Babiloni C, Binetti G, Cassetta E, Cerboneschi D, Dal Forno G, Del Percio C, Ferreri F, Ferri R, Lanuzza B, Miniussi C, Moretti DV, Nobili F, Pascual-Marqui RD, Rodriguez G, Romani GL, Salinari S, Tecchio F, Vitali P, Zanetti O, Zappasodi F, Rossini PM. Mapping distributed sources of cortical rhythms in mild Alzheimers disease. A multi-centric EEG study. Neuroimage 2004;22(1):57-67.

Babiloni C, Ferri R, Moretti DV, Strambi A, Binetti G, Dal Forno G, Ferreri F, Lanuzza B, Bonato C, Nobili F, Rodriguez G, Salinari S, Passero S, Rocchi R, Stam CJ, Rossini PM. Abnormal fronto-parietal coupling of brain rhythms in mild Alzheimer's disease: a multicentric EEG study. Eur J Neurosci 2004;19(9):2583-90.

Babiloni C, Babiloni F, Carducci F, Cappa S, Cincotti F, Del Percio C, Miniussi C, Moretti DV, Rossi S, Sosta K, Rossini PM. Human cortical rhythms during visual delayed choice reaction time tasks. A highresolution EEG study on normal aging. Behav Brain Res 2004;153(1): 261-71.

Babiloni C, Miniussi C, Babiloni F, Carducci F, Cincotti F, Del Percio C, Sirello G, Sosta K, Nobre AC, Paolo M, Rossini PM. Sub-second 'temporal attention' modulates alpha rhythms. A high-resolution EEG study. Brain Res Cogn Brain Res 2004;19(3):259-68.

Babiloni C, Babiloni F, Carducci F, Cappa S, Cincotti F, Del Percio C, Miniussi C, Moretti DV, Rossi S, Sosta K, Rossini PM. Human cortical responses during one-bit short-term memory. A high-resolution EEG study on delayed choice reaction time tasks. Clin Neurophysiol 2004; (1):161-70.

Babiloni C, Babiloni F, Carducci F, Cappa S, Cincotti F, Del Percio C, Miniussi C, Moretti DV, Pasqualetti P, Rossi S, Sosta K, Rossini PM. Human cortical EEG rhythms during long-term episodic memory task. A high resolution EEG study of the HERA model. Neuroimage 2004; 21(4):1576-84.

Babiloni C, Binetti G, Cassarino A, Dal Forno G, Del Percio C, Ferreri F, Ferri R, Frisoni G, Galderisi S, Hirata K, Lanuzza B, Miniussi C, Mucci A, Nobili F, Rodriguez G, Romani GL, Rossini PM. Sources of cortical rhythms in adults during physiological aging: a multi-centric EEG study. Hum Brain Mapp 2005 Aug 17; [Epub ahead of print].

Babiloni C, Cassetta E, Chiovenda P, Del Percio C, Ercolani M, Moretti DV, Moffa F, Pasqualetti P, Pizzella V, Romani GL, Tecchio F, Zappasodi F, Rossini PM. Frontomedial alpha hyper-reactivity in mild demented patients during visual delayed response tasks. A MEG study. Brain Res Bull 2005; 65(6):457-70.

Babiloni C, Babiloni F, Carducci F, Cincotti F, Del Percio C, Della Penna S, Franciotti R, Pignotti S, Pizzella V, Rossini PM, Sabatini E, Torquati K, Romani GL. Human alpha rhythms during visual delayed choice reaction time tasks. A MEG study. Hum Brain Mapp 2005;24(3): 184-92. Erratum in: Hum Brain Mapp 2005;24(4):332.

Bachman DL, Wolf PA, Linn RT, Knoefel JE, Cobb JL, Belanger AJ, White LR, D'Agostino RB. Incidence of dementia and probable Alzheimer's disease in a general population. The Framingham Study. Neurology 1993;43:515-9.

Baron JC, Chetelat G, Desgranges B, Perchey G, Landeau B, de la Sayette V, Eustache F. In vivo mapping of gray matter loss with voxelbased morphometry in mild Alzheimer's disease. Neuroimage 2001; 14(2):298-309.

Bennett DA, Wilson RS, Schneider JA, Evans DA, Beckett LA, Aggarwal NT, Barnes LL, Fox JH, Bach J. Natural history of mild cognitive impairment in older persons. Neurology 2002;59: 198-205.
Besthorn C, Zerfass R, Geiger-Kabisch C, Sattel H, Daniel S, SchreiterGasser U, Forstl H. Discrimination of Alzheimer's disease and normal aging by EEG data. Electroencephalogr Clin Neurophysiol 1997; 103(2):241-8.

Braak H, Braak E. Neuropathological stageing of Alzheimer-related changes. Acta Neuropathol 1991;82:239-59.

Brassen S, Adler G. Short-term effects of acetylcholinesterase inhibitor treatment on EEG and memory performance in Alzheimer patients: an open, controlled trial. Pharmacopsychiatry 2003;36(6):304-8.

Brenner RP, Ulrich RF, Spiker DG, Sclabassi RJ, Reynolds III CF, Marin RS, Boller F. Computerized EEG spectral analysis in elderly normal, demented and depressed subjects. Electroencephalogr Clin Neurophysiol 1986;64:483-92.

Brunia CH. Neural aspects of anticipatory behavior. Acta Psychol (Amsterdam) 1999;101(2-3):213-42.

Buchan RJ, Nagata K, Yokoyama E, Langman P, Yuya H, Hirata Y, Hatazawa J, Kanno I. Regional correlations between the EEG and oxygen metabolism in dementia of Alzheimer's type. Electroencephalogr Clin Neurophysiol 1997;103(3):409-17.

Callen DJ, Black SE, Gao F, Caldwell CB, Szalai JP. Beyond the hippocampus: MRI volumetry confirms widespread limbic atrophy in AD. Neurology 2001;57(9):1669-74.

Celsis P, Agniel A, Puel M, Le Tinnier A, Viallard G, Demonet JF, Rascol A, Marc-Vergnes JP. Lateral asymmetries in primary degenerative dementia of the Alzheimer type. A correlative study of cognitive, haemodynamic and EEG data, in relation with severity, age of onset and sex. Cortex 1990;26(4):585-96.

Chiaramonti R, Muscas GC, Paganini M, Muller TJ, Fallgatter AJ, Versari A, Strik WK. Correlations of topographical EEG features with clinical severity in mild and moderate dementia of Alzheimer type. Neuropsychobiology 1997;36(3):153-8.

Cincotti F, Babiloni C, Miniussi C, Carducci F, Moretti D, Salinari S, Pascual-Marqui R, Rossini PM, Babiloni F. EEG deblurring techniques in a clinical context. Methods Inf Med 2004;43(1):114-7.

Coben LA, Danziger WL, Berg L. Frequency analysis of the resting awake EEG in mild senile dementia of Alzheimer type. Electroencephalogr Clin Neurophysiol 1983;55(4):372-80.

Cook IA, Leuchter AF. Synaptic dysfunction in Alzheimer's disease: clinical assessment using quantitative EEG. Behav Brain Res 1996; 78(1):15-23.

Devanand DP, Folz M, Gorlyn M, Moeller JR, Stern J. Questionable dementia: clinical course and predictors of outcome. J Am Geriatr Soc 1997;45:321-8.

Dierks T, Ihl R, Frolich L, Maurer K. Dementia of the Alzheimer type: effects on the spontaneous EEG described by dipole sources. Psychiatry Res 1993;50(3):51-162.

Dierks T, Jelic V, Pascual-Marqui RD, Wahlund LO, Julin P, Linden DEJ, Maurer K, Winblad B, Nordberg A. Spatial pattern of cerebral glucose metabolism (PET) correlates with localization of intracerebral EEGgenerators in Alzheimer's disease. Clin Neurophysiol 2000;111(10): $1817-24$.

Dossi RC, Nunez A, Steriade M. Electrophysiology of a slow $(0.5-4 \mathrm{~Hz})$ intrinsic oscillation of cat thalamocortical neurones in vivo. J Physiol 1992;447:215-34.

Elmstahl S, Rosen I. Postural hypotension and EEG variables predict cognitive decline: results from a 5-year follow-up of healthy elderly women. Dement Geriatr Cogn Disord 1997;8(3):180-7.

Fernandez A, Arrazola J, Maestu F, Amo C, Gil-Gregorio P, Wienbruch C, Ortiz T. Correlations of hippocampal atrophy and focal low-frequency magnetic activity in Alzheimer disease: volumetric MR imagingmagnetoencephalographic study. AJNR Am J Neuroradiol 2003;24(3): 481-7.

Ferreri F, Pauri F, Pasqualetti P, Fini F, Dal Forno G, Rossini PM. Motor cortex excitability in Alzheimer's disease: a transcranial magnetic stimulation study. Ann Neurol 2003;53(1):102-8.

Ferri R, Del Gracco S, Elia M, Musumeci SA, Spada R, Stefanini MC. Scalp topographic mapping of middle-latency somatosensory evoked 
potentials in normal aging and dementia. Neurophysiol Clin 1996; 26(5):311-9.

Fisk JD, Merry HR, Rockwood K. Variations in case definition affect prevalence but not outcomes of mild cognitive impairment. Neurology 2003;61:1179-84.

Flicker CS, Ferris H, Reisberg B. Mild cognitive impairment in the elderly: predictors of dementia. Neurology 1991;41:1006-9.

Folstein MF, Folstein SE, McHugh PR. 'Mini mental state': a practical method for grading the cognitive state of patients for clinician. J Psychiatr Res 1975;12:189-98.

Frisoni GB, Beltramello A, Binetti G, Bianchetti A, Weiss C, Scuratti A, Trabucchi M. Related articles, computed tomography in the detection of the vascular component in dementia. Gerontology 1995;41(2):121-8.

Frodl T, Hampel H, Juckel G, Burger K, Padberg F, Engel RR, Moller HJ, Hegerl U. Value of event-related P300 subcomponents in the clinical diagnosis of mild cognitive impairment and Alzheimer's disease. Psychophysiology 2002;39(2):175-81.

Fuchs M, Wagner M, Kastner J. Boundary element method volume conductor models for EEG source reconstruction. Clin Neurophysiol 2001;112(8):1400-7.

Galluzzi S, Cimaschi L, Ferrucci L, Frisoni GB. Mild cognitive impairment: clinical features and review of screening instruments. Aging 2001;13(3): 183-202.

Galluzzi S, Sheu CF, Zanetti O, Frisoni GB. Distinctive clinical features of mild cognitive impairment with subcortical cerebrovascular disease. Dement Geriatr Cogn Disord 2005;19(4):196-203.

Gao S, Hendrie HC, Hall KS, Hui S. The relationships between age, sex, and the incidence of dementia and Alzheimer's disease. A metaanalysis. Arch Gen Psychiatry 1998;55:809-15.

Geula C, Mesulam MM. Cortical cholinerigc fibers in aging and Alzheimer's disease: a morphometirc study. Neuroscience 1989;33: 469-81.

Geula C, Mesulam MM. Systematic regional variations in the loss of cortical cholinergic fibers in Alzheimer's disease. Cereb Cortex 1996;6: 165-77.

Geula C, Mesulam MM. Cholinergic system in Alzheimer's disease. In: Terry RD, Katzman R, Bick KL, Sisodia SS, editors. Alzheimer disease. 2nd ed. Philadelphia, PA: Lippincot, Williams and Wilkins; 1999. p. 69-292.

Goforth HW, Konopka L, Primeau M, Ruth A, O’Donnell K, Patel R, Poprawski T, Shirazi P, Rao M. Quantitative electroencephalography in frontotemporal dementia with methylphenidate response: a case study. Clin EEG Neurosci 2004;35(2):108-11.

Gross J, Timmermann L, Kujala J, Salmelin R, Schnitzler A. Properties of MEG tomographic maps obtained with spatial filtering. Neuroimage 2003;19(4):1329-36.

Grunwald M, Busse F, Hensel A, Kruggel F, Riedel-Heller S, Wolf H, Arendt T, Gertz HJ. Related articles, links correlation between cortical theta activity and hippocampal volumes in health, mild cognitive impairment, and mild dementia. J Clin Neurophysiol 2001;18(2): $178-84$.

Grunwald M, Busse F, Hensel A, Riedel-Heller S, Kruggel F, Arendt T, Wolf H, Gertz HJ. Theta-power differences in patients with mild cognitive impairment under rest condition and during haptic tasks. Alzheimer Dis Assoc Disord 2002;16(1):40-8.

Holschneider DP, Leuchter AF, Scremin OU, Treiman DM, Walton NW. Effects of cholinergic deafferentation and NGF on brain electrical coherence. Brain Res Bull 1998;45:531-41.

Holschneider DP, Waite JJ, Leuchter AF, Walton NY, Scremin OU. Changes in electrocortical power and coherence in response to the selective cholinergic immunotoxin 192 IgG-saporin. Exp Brain Res 1999;126(2):270-80.

Huang C, Wahlund LO, Dierks T, Julin P, Winblad B, Jelic V. Discrimination of Alzheimer's disease and mild cognitive impairment by equivalent EEG sources: a cross-sectional and logitudinal study. Clin Neurophysiol 2000;11:1961-7.
Huang C, Wahlund LO, Svensson L, Winblad B, Julin P. Cingulate cortex hypoperfusion predicts Alzheimer's disease in mild cognitive impairment. BMC Neurol 2002;2(1):9.

Hughes CP, Berg L, Danziger WL, Cohen LA, Martin RL. A new clinical rating scale for the staging of dementia. Br J Psychiatry 1982;140: 1225-30

Ihl R, Eilles C, Frlich L, Maurer K, Dierks T, Perisic I. Electrical brain activity and cerebral blood flow in dementia of the Alzheimer type. Psychiatry Res 1989;29(3):449-52.

Isotani T, Lehmann D, Pascual-Marqui RD, Kochi K, Wackermann J, Saito N, Yagyu T, Kinoshita T, Sasada K. EEG source localization and global dimensional complexity in high- and low- hypnotizable subjects: a pilot study. Neuropsychobiology 2001;44(4):192-8.

Jelic V, Shigeta M, Julin P. Quantitative electroencephalography power and coherence in Alzheimer's disease and mild cognitive impairment. Dementia 1996;7:314-23.

Jelic V, Johansson SE, Almkvist O, Shigeta M, Julin P, Nordberg A, Winblad B, Wahlund LO. Quantitative electroencephalography in mild cognitive impairment: longitudinal changes and possible prediction of Alzheimer's disease. Neurobiol Aging 2000;21(4):533-40.

Julin P, Wahlund LO, Basun H, Persson A, Mare K, Rudberg U. Clinical diagnosis of frontal lobe dementia and Alzheimer disease: relation to cerebral perfusion, brain atrophy and electroencephalography. Dement Geriatr Cogn Disord 1995;6:142-7.

Joannesson G, Brun A, Gustafson I, Ingvar DH. EEG in presenile dementia related to cerebral blood flow and autopsy findings. Acta Neurol Scand 1977;56:89-103.

Johnson KA, Jones K, Holman BL, Becker JA, Spiers PA, Satlin A, Albert MS. Preclinical prediction of Alzheimer's disease using SPECT. Neurology 1998;50(6):1563-71.

Kawasaki T, Tanaka S, Wang J, Hokama H, Hiramatsu K. Abnormalities of P300 cortical current density in unmedicated depressed patients revealed by LORETA analysis of event-related potentials. Psychiatry Clin Neurosci 2004;58(1):68-75.

Killiany RJ, Moss MB, Albert MS, Sandor T, Tieman J, Jolesz F. Temporal lobe regions on magnetic resonance imaging identify patients with early Alzheimer's disease. Arch Neurol 1993;50(9):949-54.

Kitayama N, Matsuda H, Ohnishi T, Kogure D, Asada T, Uno M, Kamijima K. Measurements of both hippocampal blood flow and hippocampal gray matter volume in the same individuals with Alzheimer's disease. Nucl Med Commun 2001;22(5):473-7.

Klimesch W. Memory processes, brain oscillations and EEG synchronization. Int J Psychophysiol 1996;24(1-2):61-100.

Klimesch W. EEG alpha and theta oscillations reflect cognitive and memory performance: a review and analysis. Brain Res Brain Res Rev 1999;29:169-95.

Klimesch W, Doppelmayr M, Pachinger T, Russegger H. Event-related desynchronization in the alpha band and the processing of semantic information. Brain Res Cogn Brain Res 1997;6(2):83-94.

Klimesch W, Doppelmayr M, Russegger H, Pachinger T, Schwaiger J. Induced alpha band power changes in the human EEG and attention. Neurosci Lett 1998;244(2):73-6.

Kobayashi Y, Tadashi I. Sensory-motor gating and cognitive control by the brainstem cholinergic system. Neural Netw 2002;731-41.

Kolev V, Yordanova J, Basar-Eroglu C, Basar E. Age effects on visual EEG responses reveal distinct frontal alpha networks. Clin Neurophysiol 2002;113(6):901-10.

Kwa VI, Weinstein HC, Posthumus Meyjes EF, van Royen EA, Bour LJ, Verhoeff PN, Ongerboer de Visser BW. Spectral analysis of the EEG and $99 \mathrm{~m}-\mathrm{Tc}-\mathrm{HMPAO}$ SPECT-scan in Alzheimer's disease. Biol Psychiatry 1993;33(2):100-7.

Larrieu S, Letenneur L, Orgogozo JM, Fabrigoule C, Amieva H, Le Carret N, Barberger-Gateau P, Dartigues JF. Incidence and outcome of mild cognitive impairment in a population-based prospective cohort. Neurology 2002;59:1594-9.

Laufer I, Pratt H. Evoked potentials to auditory movement sensation in duplex perception. Clin Neurophysiol 2003a;114(7):1316-31. 
Laufer I, Pratt H. The electrophysiological net response ('F-complex') to spatial fusion of speech elements forming an auditory object. Clin Neurophysiol 2003b;114(5):818-34.

Lawton MP, Brodie EM. Assessment of older people: self maintaining and instrumental activity of daily living. J Gerontol 1969;9:179-86.

Leuchter AF, Cook IA, Newton TF, Dunkin J, Walter DO, Rosenberg Tompson S. Regional differences in brain electrical activity in dementia: use of spectral power and spectral ratio measures. Electroencephalogr Clin Neurophysiol 1993;87:385-93.

Lopes da Silva FH, van Rotterdam A, Barts P, van Heusden E, Burr W. Models of neuronal populations: the basic mechanisms of rhythmicity. Prog Brain Res 1976;45:281-308.

Lopes da Silva F, Pijn JP, Boeijinga P. Interdependence of EEG signals: linear vs. nonlinear associations and the significance of time delays and phase shifts. Brain Topogr 1989;2(1-2):9-18.

Mash DC, Flynn DD, Potter LT. Loss of M2 muscarine receptors in the cerebral cortex in Alzheimer's disease and experimental cholinergic denervation. Science 1985;228(4703):1115-7.

Mattia D, Babiloni F, Romigi A, Cincotti F, Bianchi L, Sperli F, Placidi F, Bozzao A, Giacomini P, Floris R, Grazia Marciani M. Quantitative EEG and dynamic susceptibility contrast MRI in Alzheimer's disease: a correlative study. Clin Neurophysiol 2003;114(7):1210-6.

Mazur A, Pace-Schott EF, Hobson JA. The prefrontal cortex in sleep. Trends Cogn Sci 2002;6:475-481.

McKhann G, Drachman D, Folstein M, Katzman R, Price D, Stadlan EM. Clinical diagnosis of Alzheimer's disease: report of the NINCDSADRDA work group under the auspices of Department of Health and Human Services Task Force on Alzheimer's disease. Neurology 1984; 34:939-44.

Mesulam M. The cholinergic lesion of Alzheimer's disease: pivotal factor or side show? Learn Mem 2004;11:43-9.

Minoshima S, Foster NL, Kuhl DE. Posterior cingulate cortex in Alzheimer's disease. Lancet 1994;344(8926):895.

Moretti DV, Babiloni F, Carducci F, Cincotti F, Remondini E, Rossini PM, Salinari S, Babiloni C. Computerized processing of EEG-EOG-EMG artifacts for multicentirc studies in EEG oscillations and event-related potentials. Int J Psychophysiol 2003;47(3):199-216.

Moretti DV, Babiloni C, Binetti G, Cassetta E, Dal Forno G, Ferreri F, Lanuzza Bartolo, Miniussi C, Nobili F, Rodriguez G, Salinari S, Rossini PM. Individual analysis of EEG frequency and band power in mild Alzheimer's disease. Clin Neurophysiol 2004;115:299-308.

Mulert C, Gallinat J, Pascual-Marqui R, Dorn H, Frick K, Schlattmann P, Mientus S, Herrmann WM, Winterer G. Reduced event-related current density in the anterior cingulate cortex in schizophrenia. Neuroimage 2001;13(4):589-600.

Muller TJ, Thome J, Chiaramonti R, Dierks T, Maurer K, Fallgatter AJ, Frolich L, Scheubeck M, Strik WK. A comparison of qEEG and HMPAO-SPECT in relation to the clinical severity of Alzheimer's disease. Eur Arch Psychiatry Clin Neurosci 1997;247(5):259-63.

Niedermeyer E. Alpha rhythms as physiological and abnormal phenomena. Int J Psychophysiol 1997;26:31-49.

Nobili F, Taddei G, Vitali P, Bazzano L, Catsafados E, Mariani G, Rodriguez G. Relationships between 99m Tc-HMPAO ceraspect and quantitative EEG observations in Alzheimer's disease. Arch Gerontol Geriatr 1998;6:363-8.

Nobili F, Vitali P, Canfora M, Girtler N, De Leo C, Mariani G, Pupi A, Rodriguez G. Effects of long-term Donepezil therapy on rCBF of Alzheimer's patients. Clin Neurophysiol 2002a;113(8):1241-8.

Nobili F, Koulibaly M, Vitali P, Migneco O, Mariani G, Ebmeier K, Pupi A, Robert PH, Rodriguez G, Darcourt J. Brain perfusion follow-up in Alzheimer's patients during treatment with acetylcholinesterase inhibitors. J Nucl Med 2002b;43(8):983-90.

Nunez PL, Wingeier BM, Silberstein RB. Spatial-temporal structures of human alpha rhythms: theory, microcurrent sources, multiscale measurements, and global binding of local networks. Hum Brain Mapp 2001;13(3):125-64
Nuwer MR. Quantitative EEG. I: tecniques and problems of frequency analysis and topographic mapping. J Clin Neurophysiol 1988;5:1-43.

Okamura N, Arai H, Maruyama M, Higuchi M, Matsui T, Tanji H, Seki T, Hirai H, Chiba H, Itoh M, Sasaki H. Combined analysis of CSF tau levels and [(123)I]iodoamphetamine SPECT in mild cognitive impairment: implications for a novel predictor of Alzheimer's disease. Am J Psychiatry 2002;159(3):474-6.

Osipova D, Ahveninen J, Kaakkola S, Jaaskelainen IP, Huttunen J, Pekkonen E. Effects of scopolamine on MEG spectral power and coherence in elderly subjects. Clin Neurophysiol 2003;114(10):1902-7.

Pascual-Marqui RD, Michel CM. LORETA (low resolution brain electromagnetic tomography): new authentic 3D functional images of the brain. ISBET Newsletter 1994;5:4-8.

Pascual-Marqui RD, Lehmann D, Koenig T, Kochi K, Merlo MC, Hell D, Koukkou M. Low resolution brain electromagnetic tomography (LORETA) functional imaging in acute, neuroleptic-naive, firstepisode, productive schizophrenia. Psychiatry Res 1999;90(3):169-79.

Pascual-Marqui RD, Esslen M, Kochi K, Lehmann D. Functional imaging with low resolution brain electromagnetic tomography (LORETA): a review. Methods Find Exp Clin Pharmacol 2002;24:91-5.

Passero S, Rocchi R, Vatti G, Burgalassi L, Battistini N. Quantitative EEG mapping, regional cerebral blood flow, and neuropsychological function in Alzheimer's disease. Dementia 1995;6:148-56.

Pennisi G, Alagona G, Ferri R, Greco S, Santonocito D, Pappalardo A, Bella R. Motor cortex excitability in Alzheimer disease: one year follow-up study. Neurosci Lett 2002;329(3):293-6.

Petersen RC, Smith GE, Ivnik RJ, Tangalos EG, Schaid SN, Thibodeau SN, Kokmen E, Waring SC, Kurland LT. Apolipoprotein E status as a predictor of the development of Alzheimer's disease in memoryimpaired individuals. JAMA 1995;273:1274-8.

Petersen RC, Smith GE, Waring SC, Ivnik RJ, Kokmen E, Tangelos EG. Aging, memory, and mild cognitive impairment. Int Psychogeriatr 1997;9(Suppl. 1):65-9

Petersen RC, Smith GE, Waring SC, Ivnik RJ, Tangalos EG, Kokmen E. Mild cognitive impairment: clinical characterization and outcome. Arch Neurol 1999;56:303-8.

Petersen RC, Doody R, Kurz A, Mohs RC, Morris JC, Rabins PV, Ritchie K, Rossor M, Thal L, Winblad B. Current concepts in mild cognitive impairment. Arch Neurol 2001;58(12):1985-92.

Pfurtscheller G, Lopez da Silva F. Event-related EEG/MEG synchronization and desynchronization: basic principles. Clin Neurophysiol 1999; 110:1842-57.

Ponomareva NV, Selesneva ND, Jarikov GA. EEG alterations in subjects at high familial risk for Alzheimer's disease. Neuropsychobiology 2003; 48(3):152-9.

Prichep LS, John ER, Ferris SH, Reisberg B, Almas M, Alper K, Cancro R. Quantitative EEG correlates of cognitive deterioration in the elderly. Neurobiol Aging 1994;15(3):391.

Priori A, Foffani G, Pesenti A, Tamma F, Bianchi AM, Pellegrini M, Locatelli M, Moxon KA, Villani RM. Rhythm-specific pharmacological modulation of subthalamic activity in Parkinson's disease. Exp Neurol 2004;189(2):369-79.

Pucci E, Cacchiò G, Angeloni R, Belardinelli N, Nolfe G, Signorino M, Angeleri F. EEG spectral analysis in Alzheimer's disease and different degenerative dementias. Arch Gerontol Geriatr 1997;26:283-97.

Pucci E, Belardinelli N, Cacchio G, Signorino M, Angeleri F. EEG power spectrum differences in early and late onset forms of Alzheimer's disease. Clin Neurophysiol 1999;110(4):621-31.

Rae-Grant A, Blume W, Lau C, Hachinski VC, Fisman M, Merskey H. The electroencephalogram in Alzheimer-type dementia. A sequential study correlating the electroencephalogram with psychometric and quantitative pathologic data. Arch Neurol 1987;44(1):50-4.

Ricceri L, Minghetti L, Moles A, Popoli P, Confaloni A, De Simone R, Piscopo P, Scattoni ML, di Luca M, Calamandrei G. Cognitive and neurological deficits induced by early and prolonged basal forebrain cholinergic hypofunction in rats. Exp Neurol 2004;189(1):162-72. 
Rodriguez G, Nobili F, Rocca G, DeCarli F, Gianelli MV, Rosadini G. Quantitative electroencephalography and regional cerebral blood flow: discriminant analysis between Alzheimer's patients and healthy controls. Dement Geriatr Cogn Disord 1998;9:238-74.

Rodriguez G, Copello F, Nobili F, Vitali P, Perego G, Nobili F. EEG spectral profile to stage Alzheimer's disease. Clin Neurophysiol 1999a; 110:1831-7.

Rodriguez G, Nobili F, Copello F, Vitali P, Gianelli MV, Taddei G, Catsafados E, Mariani G. 99mTc-HMPAO regional cerebral blood flow and quantitative electroencephalography in Alzheimer's disease: a correlative study. J Nucl Med 1999b;40:522-9.

Rodriguez G, Vitali P, Calvini P, Bordoni C, Girtler N, Taddei G, Mariani G, Nobili F. Hippocampal perfusion in mild Alzheimer's disease. Psychiatry Res 2000;100(2):65-74.

Rodriguez G, Vitali P, De Leo C, De Carli F, Girtler N, Nobili F. Quantitative EEG changes in Alzheimer patients during long-term donepezil therapy. Neuropsychobiology 2002;46:49-56.

Rogers J, Webster S, Lue LF, Brachova L, Civin WH, Emmerling M, Shivers B, Walker D, McGeer P. Inflammation and Alzheimer's disease pathogenesis. Neurobiol Aging 1996;17(5):681-6.

Roman GC, Tatemichi TK, Erkinjuntti T, Cummings JL, Masdeu JC, Garcia JH, Amaducci L, Orgogozo JM, Brun A, Hofman A, et al. Vascular dementia: diagnostic criteria for research studies. Report of the NINDS-AIREN international workshop. Neurology 1993;43(2): 250-60.

Rosen WG, Terry RD, Fuld PA, Katzman R, Peck A. Pathological verification of ischemic score in differentiation of dementias. Ann Neurol 1980;7(5):486-8.

Rubin EH, Morris JC, Grant EA, Vendegna T. Very mild senile dementia of the Alzheimer type. I. Clinical assessment. Arch Neurol 1989;46: 379-82.

Saletu B, Anderer P, Saletu-Zyhlarz GM, Pascual-Marqui RD. EEG topography and tomography in diagnosis and treatment of mental disorders: evidence for a key-lock principle. Methods Find Exp Clin Pharmacol 2002;24(Suppl. D):97-106.

Sarter M, Bruno JP. Cognitive functions of cortical acetylcholine: toward a unifying hypothesis. Brain Res Brain Res Rev 1997;23(1-2):28-46.

Sarter M, Bruno JP. Age-related changes in rodent cortical acetylcholine and cognition: main effects of age versus age as an intervening variable. Brain Res Brain Res Rev 1998;27(2):143-56.

Scheltens P, Fox N, Barkhof F, De Carli C. Structural magnetic resonance imaging in the practical assessment of dementia: beyond exclusion. Lancet Neurol 2002;1(1):13-21.

Sekihara K, Sahani M, Nagarajan SS. Localization bias and spatial resolution of adaptive and non-adaptive spatial filters for MEG source reconstruction. Neuroimage 2005;25(4):1056-67.

Sheridan PH, Sato S, Foster N, Bruno G, Cox C, Fedio P, Chase TN. Relation of EEG alpha background to parietal lobe function in Alzheimer's disease as measured by positron emission tomography and psychometry. Neurology 1988;38:747-50.

Singer W. Synchronization of cortical activity and its putative role in information processing and learning. Annu Rev Physiol 1993;55: 349-74.

Sloan EP, Fenton GW, Kennedy NSJ, MacLennan JM. Electroencephalography and single photon emission computed tomography in dementia: a comparative study. Psychol Med 1995;25:631-8.

Small GW, Rabins PV, Barry PP, Buckholtz NS, DeKosky ST, Ferris SH, Finkel SI, Gwyther LP, Khachaturian ZS, Lebowitz BD, McRae TD,
Morris JC, Oakley F, Schneider LS, Streim JE, Sunderland T, Teri LA, Tune LE. Diagnosis and treatment of Alzheimer disease and related disorders. Consensus statement of the American Association for Geriatric Psychiatry, the Alzheimer's Association, and the American Geriatrics Society. JAMA 1997;278(16):1363-71.

Steriade M. The corticothalamic system in sleep. Front Biosci 2003;8: d878-d99.

Steriade M, Llinas RR. The functional states of the thalamus and the associated neuronal interplay. Physiol Rev 1988;68(3):649-742.

Steriade M, Amzica F, Contreras D. Cortical and thalamic cellular correlates of electroencephalographic burst-suppression. Electroencephalogr Clin Neurophysiol 1994;90(1):1-16.

Stigsby B, Johannesson G, Ingvar DH. Regional EEG analysis and regional cerebral blood flow in Alzheimer's and Pick's diseases. Electroencephalogr Clin Neurophysiol 1981;51:537-47.

Szava S, Valdés P, Biscay R, Galán L, Bosch J, Clark I, Jimenez JC. High resolution quantitative EEG analysis. Brain Topogr 1994;6:211-9.

Szelies B, Grond M, Herholz K, Kessler J, Wullen T, Heiss WD. Quantitative EEG mapping and PET in Alzheimer's disease. J Neurol Sci 1992;110:46-56.

Szelies B, Mielke R, Kessler J, Heiss WD. EEG power changes are related to regional cerebral glucose metabolism in vascular dementia. Clin Neurophysiol 1999;110(4):615-20.

Talairach J, Tournoux P. Co-planar stereotaxic atlas of the human brain. Stuttgart: Thieme; 1988.

Tanaka Y, Hanyu H, Sakurai H, Takasaki M, Abe K. Atrophy of the substantia innominata on magnetic resonance imaging predicts response to donepezil treatment in Alzheimer's disease patients. Dement Geriatr Cogn Disord 2003;16:119-25.

Tononi G, Sporns O, Edelman GM. A measure for brain complexity: relating functional segregation and integration in the nervous system. Proc Natl Acad Sci USA 1994;91(11):5033-7.

Valdes P, Picton TW, Trujillo N, Bosch J, Aubert E, Riera J. Constraining EEG-MEG source imaging with statistical neuroanatomy. Neuroimage 1998;4:635.

Veiga H, Deslandes A, Cagy M, Fiszman A, Piedade RA, Ribeiro P. Neurocortical electrical activity tomography in chronic schizophrenics. Arq Neuropsiquiatr 2003;61(3B):712-7 [Epub 2003 Oct 28].

Winterer G, Mulert C, Mientus S, Gallinat J, Schlattmann P, Dorn H, Herrmann WM. P300 and LORETA: comparison of normal subjects and schizophrenic patients. Brain Topogr 2001;13(4):299-313.

Wolf H, Jelic V, Gerts H-J, Nordberg A, Julin P, Wahlund L-O. A critical discussion of the role of neuroimaging in mild cognitive impairment. Acta Neurol Scand 2003;107:52-76.

Yesavage JA, Brink TL, Rose TL, Lum O, Huang V, Adey M, Leirer VO. Development and validation of a geriatric depression screening scale: a preliminary report. J Psychiatr Res 1982-83;17(1):37-49.

Young AB. Cortical amino acidergic pathways in Alzheimer's disease. J Neural Transm Suppl 1987;24:147-52.

Zappoli R, Versari A, Paganini M, Arnetoli G, Muscas GC, Gangemi PF, Arneodo MG, Poggiolini D, Zappoli F, Battaglia A. Brain electrical activity (quantitative EEG and bit-mapping neurocognitive CNV components), psychometrics and clinical findings in presenile subjects with initial mild cognitive decline or probable Alzheimer-type dementia. Ital J Neurol Sci 1995;16(6):341-76.

Zaudig M. A new systematic method of measurement and diagnosis of 'mild cognitive impairment' and dementia according to ICD-10 and DSM-III-R criteria. Int Psychogeriatr 1992;4(Suppl. 2):203-19. 